CUADERNOS DE ESTUDIOS GALLEGOS, LX Núm. 126 (enero-diciembre 2013), págs. 295-335

ISSN: 0210-847 X

DOI: $10.3989 /$ ceg.2013.126.08

\title{
COROGRAFÍAS DE SANTIAGO DE COMPOSTELA: LA VISTA DE LA CIUDAD MONUMENTAL DEL ARQUITECTO JUAN LÓPEZ FREIRE, HIJO (1799)*
}

\author{
Miguel TAÍn GuZMán \\ Universidad de Santiago de Compostela
}

\footnotetext{
La investigación aquí expuesta forma parte del proyecto de investigación La visión del artista. Ciudad y arquitectura en Galicia desde la Edad Media hasta la irrupción de la fotografía (HAR2011-24968) concedido por el Ministerio de Economía y Competitividad para el trienio 2012-2014.
} 


\title{
COROGRAFÍAS DE SANTIAGO DE COMPOSTELA: LA VISTA DE LA CIUDAD MONUMENTAL DEL ARQUITECTO JUAN LÓPEZ FREIRE, HIJO (1799)
}

\section{RESUMEN}

En 1799 el arquitecto Juan López Freire, hijo, lleva a la estampa la primera vista impresa de la ciudad de Santiago, su frente occidental. La panorámica presenta un interés ineludible para la historia de Compostela, constituyendo el primer testimonio gráfico del Santiago Monumental, resultado de las nuevas construcciones e intervenciones en el entramado urbano llevadas a cabo en los siglos XVI, XVII y XVIII. En el presente artículo se reconoce el lugar desde donde se han hecho los bocetos preparatorios, concretamente Sarela de Abaixo, y se identifican uno por uno los edificios representados, definiendo la iconografía arquitectónica de la Compostela del setecientos.

Palabras Clave: Santiago de Compostela, vista urbana, Juan López Freire hijo, Barroco, siglo XVIII.

\section{COROGRAFÍAS DE SANTIAGO DE COMPOSTELA: A VISTA DA CIDADE MONUMENTAL DO ARQUITECTO JUAN LÓPEZ FREIRE, FILLO (1799)}

\section{RESUMO}

En 1799 o arquitecto Juan López Freire, fillo, leva á estampa a primeira vista impresa da cidade de Santiago, o seu frente occidental. A panorámica presenta un interese ineludible para a historia de Compostela, constituíndo o primeiro testemuño gráfico do Santiago Monumental, resultado das novas construcións e intervencións na estructura urbana levadas a cabo nos séculos XVI, XVII e XVIII. No presente artigo localízase o lugar dende onde se fixeron os deseños preparatorios, concretamente Sarela de Abaixo, e identifícanse un por un os edificios representados, definindo a iconografía arquitectónica da Compostela do setecentos.

Palabras Clave: Santiago de Compostela, vista urbana, Juan López Freire fillo, Barroco, século XVIII.

\section{CHOROGRAPHIES OF SANTIAGO DE COMPOSTELA: THE VISION OF THE MONUMENTAL CITY OF THE ARCHITECT JUAN LÓPEZ FREIRE, JR. (1799)}

\begin{abstract}
In 1799 the architect Juan López Freire, son, made the first engraving of a view of the city of Santiago, looking towards its western façade. This panorama is of undeniable interest to the history of Compostela, as it is the first graphic record of 'Monumental Santiago,' the result of a series of new constructions and interventions in the urban layout that took place during the $16^{\text {th }}, 17$ th and $18^{\text {th }}$ centuries. This article is dedicated to the location where the preparatory sketches were made, and to identifying each of the buildings shown.

Key wORDS: Santiago de Compostela, urban view, Juan López Freire son, Baroque, $18^{\text {th }}$ century.
\end{abstract}


Recibido/Received: 25/03/2013

Aceptado/Accepted: 19/08/2013

Tradicionalmente la historiografía española viene denunciando la falta de representaciones de las ciudades del norte de España durante la Edad Moder$\mathrm{na}^{1}$. En este vacío destaca la carencia de imágenes de Santiago de Compostela, objeto, en cambio, de numerosas descripciones en la literatura odepórica de los peregrinos que hacían el Camino ${ }^{2}$. Hasta la fecha se conocían sólo dos corografías de la ciudad, las dos muy próximas cronológicamente entre sí, una debida a un miembro anónimo del séquito de Edward Mountagu, primer Conde de Sandwich, embajador inglés en España, llegado al puerto de A Coruña en 1666 , en cuyas inmediaciones hubo de quedarse varios días en cuarentena ${ }^{3}$ (fig. 1), y la otra debida a Pier Maria Baldi, artista miembro del séquito de Cosimo III de Medici, príncipe de Florencia, que visitó la ciudad en marzo de 1669 en una corta estancia ${ }^{4}$ (fig. 2). Ambas fueron realizadas para ilustrar los diarios del viaje de sus señores y no para ser llevadas a la estampa. Paradójicamente las dos se complementan, pues captan Compostela desde localizaciones muy distintas, la primera desde el monte de la Almáciga, al norte, y la segunda desde el monte de Santa Susana y el Camino Real de Pontevedra, al sur. En ellas encontramos todavía una ciudad de aspecto medieval, muy diferente al que tendrá un siglo después. En efecto, ambas presentan un núcleo densamente poblado tras las viejas murallas medio arruinadas, con la catedral románica y sus antiguas torres sobresaliendo, también con conventos, iglesias y colegios. El caserío se dispone

\footnotetext{
1 Cfr. A. Bustamante García, "Visiones de España. Los viajeros del siglo XVI y las representaciones de las ciudades", en M. Cabañas Bravo, A. López-Yarto Elizalde, W. Rincón García (eds.), El arte y el viaje, Madrid, 2011, págs. 281-294.

2 Cfr. P. CAUCCI von SAUCKen, "La memoria de Santiago y su Catedral en la literatura odepórica compostelana", Compostellanum, 1995, págs. 367-378.

3 Cfr. A. Vigo Trasancos, "La embajada a España del primer Conde de Sandwich y una vista panorámica de la ciudad de Santiago de 1666", Obradoiro de Historia Moderna, 2005, págs. 271-293.

${ }^{4}$ Cfr. J. Filgueira Valverde, "Una panorámica de Santiago en el Viaje de Cosme de Medicis", Historias de Compostela, Vigo, 1982 (1ª ed. 1970), págs. 222-226; J. Gómez Iparraguirre, I. Mera Álvarez y A. Vigo Trasancos, "Galicia en las acuarelas de Pier Maria Baldi", en X.A. Neira Cruz (comisario), El viaje a Compostela de Cosme III de Médicis, Santiago, 2004, págs. 613615; M. Taín Guzmán, La ciudad de Santiago de Compostela en 1669. La peregrinación del Gran Príncipe de la Toscana Cosimo III de Medici, Santiago, 2012, págs. 45-64.
} 


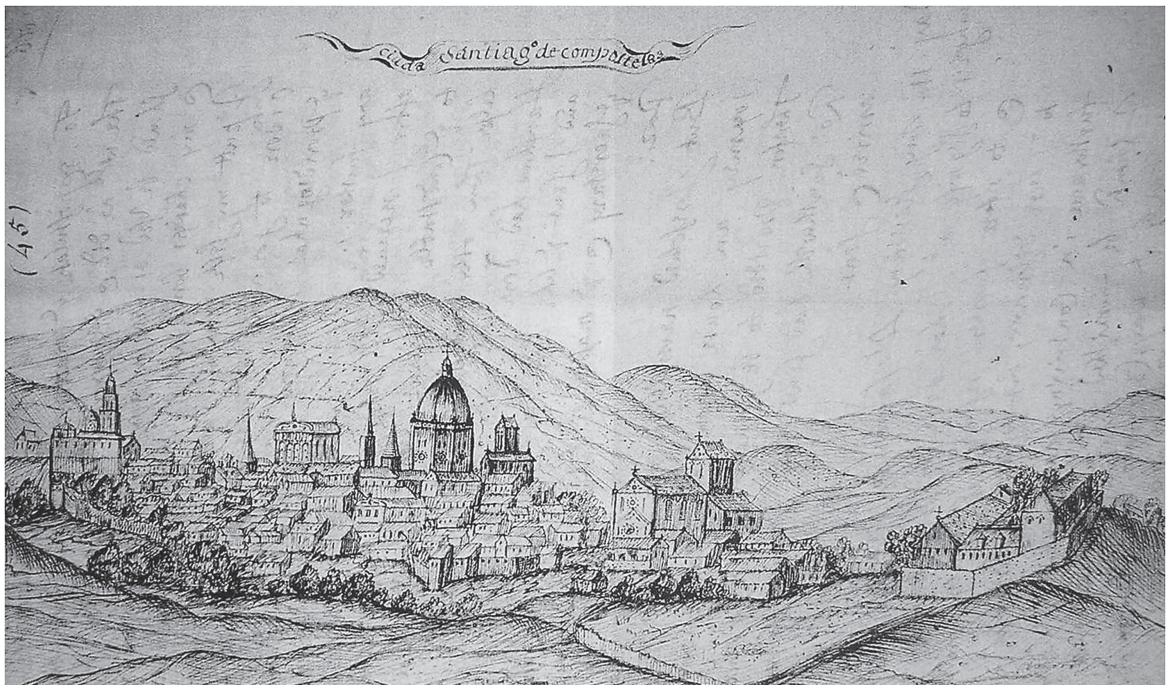

Fig. 1

Vista de la ciudad de Santiago de Compostela en 1666, según un miembro del séquito del primer Conde de Sandwich.

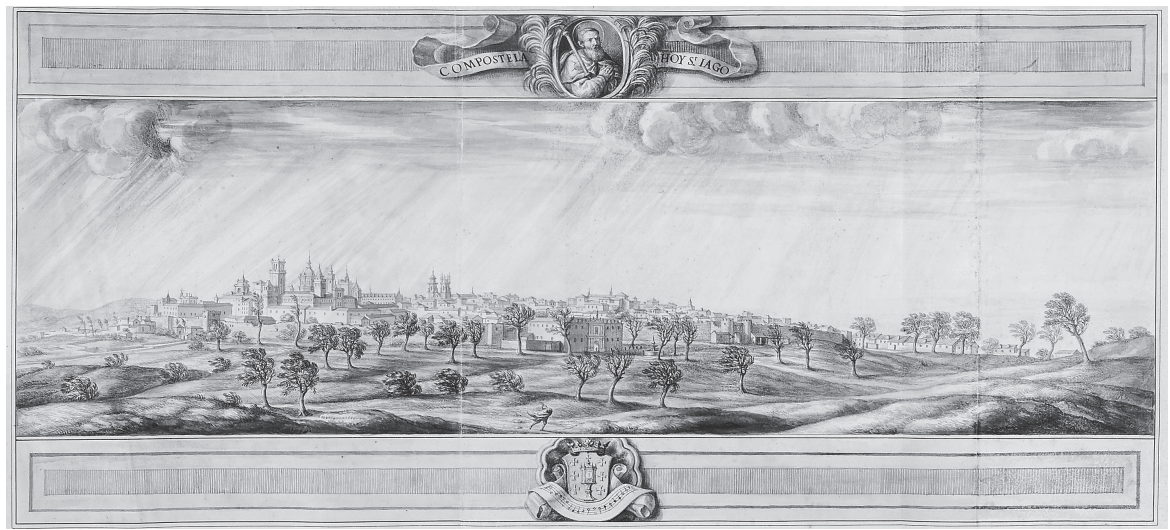

Fig. 2

Pier Maria Baldi: vista de la ciudad de Santiago de Compostela en 1669.

muy abigarrado, formado por viviendas populares, y algunas casas-torre de la nobleza, dando lugar a calles estrechas, húmedas y oscuras descritas en los relatos de los peregrinos de la época.

Las dos representaciones constituyen además un testimonio gráfico excepcional del inicio de la renovación y monumentalización de Compostela en el 
siglo XVI, de la mano de arquitectos como Enrique Egas, Juan de Álava o Rodrigo Gil de Hontañón, y sobre todo en el siglo XVII, con Ginés Martínez de Aranda, Bartolomé Fernández Lechuga, Melchor de Velasco y José de la Peña de Toro, que usan un granito de grano duro de excepcional calidad. A ellos y otros se debe la progresiva petrificación del caserío, la modernización de la catedral y las iglesias de la ciudad, la nueva construcción de edificios universitarios e institucionales, dando testimonio de todo ello la representación del Hospital Real, la iglesia de San Martín Pinario, el Palacio Capitular, la Torre del Palacio del Tesoro, el Colegio de San Jerónimo, el Colegio de Fonseca, el edificio de celdas de la Quintana del Monasterio de San Pelayo, la iglesia de San Agustín, el Colegio de San Clemente, etc. Igualmente a ellos se debe el crecimiento vertical del núcleo urbano, con la edificación de inmuebles de mayor altura y la proliferación de nuevas torres, cimborrios, linternas, balaustradas y pináculos en la catedral, iglesias y conventos, transformando Santiago para siempre. En este sentido es paradigmática la aparición en las dos corografías de la recién construida cúpula del crucero de la catedral, por aquel entonces la mayor altura de la urbe, con una presencia muy importante en las perspectivas visuales urbanas y en el entorno rural, señalando el lugar donde está enterrado el Apóstol y manifestando la reciente implantación del barroco.

La vista que ahora nos proponemos estudiar documenta la culminación de ese proceso de renovación, hallándose ya en ella presentes los edificios que hoy caracterizan Compostela.

\section{Autor, CRONOlOGía, DEDICATORIA}

En los fondos del Museo de Pontevedra he localizado una espléndida panorámica de la ciudad, ejecutada en formato apaisado, el más oportuno para recoger la mayor cantidad posible de información de los edificios y sus detalles arquitectónicos ${ }^{5}$. La hoja mide 297 milímetros de alto por 465 de ancho, la mancha 277 por 452 y la imagen de la ciudad 162 por 403, y se ha estampado con tintas a partir de una plancha de cobre donde se ha inciso la vista con buriles ${ }^{6}$ (fig. 3). Sus inscripciones nos informan de la autoría, cronología, dónde y quién lo grabó y a quien se dedica: "PLANO QUE REPRESENTA LA VISTA OCIDENTAL DE LA CIUDAD DE SANTIAGO, PRIM[ER]A DE LAS SIETE QUE CONT[IEN]E EL $R[\mathrm{EI}] N O$ DE GALICIA. Levantado y delineado por Juan López Freire, el menor, año 1799. Gravado por Manuel Navarro en Madrid. DEDICADO AL SEÑOR D[O]N JORGE CISNEROS, CANÓNIGO Y ADMINISTRADOR GENERAL DEL

\footnotetext{
5 Signatura de registro 1669-36.

6 Datos facilitados por Natalia Fraguas Fernández, Conservadora de Fondos Xerais del Museo de Pontevedra.
} 


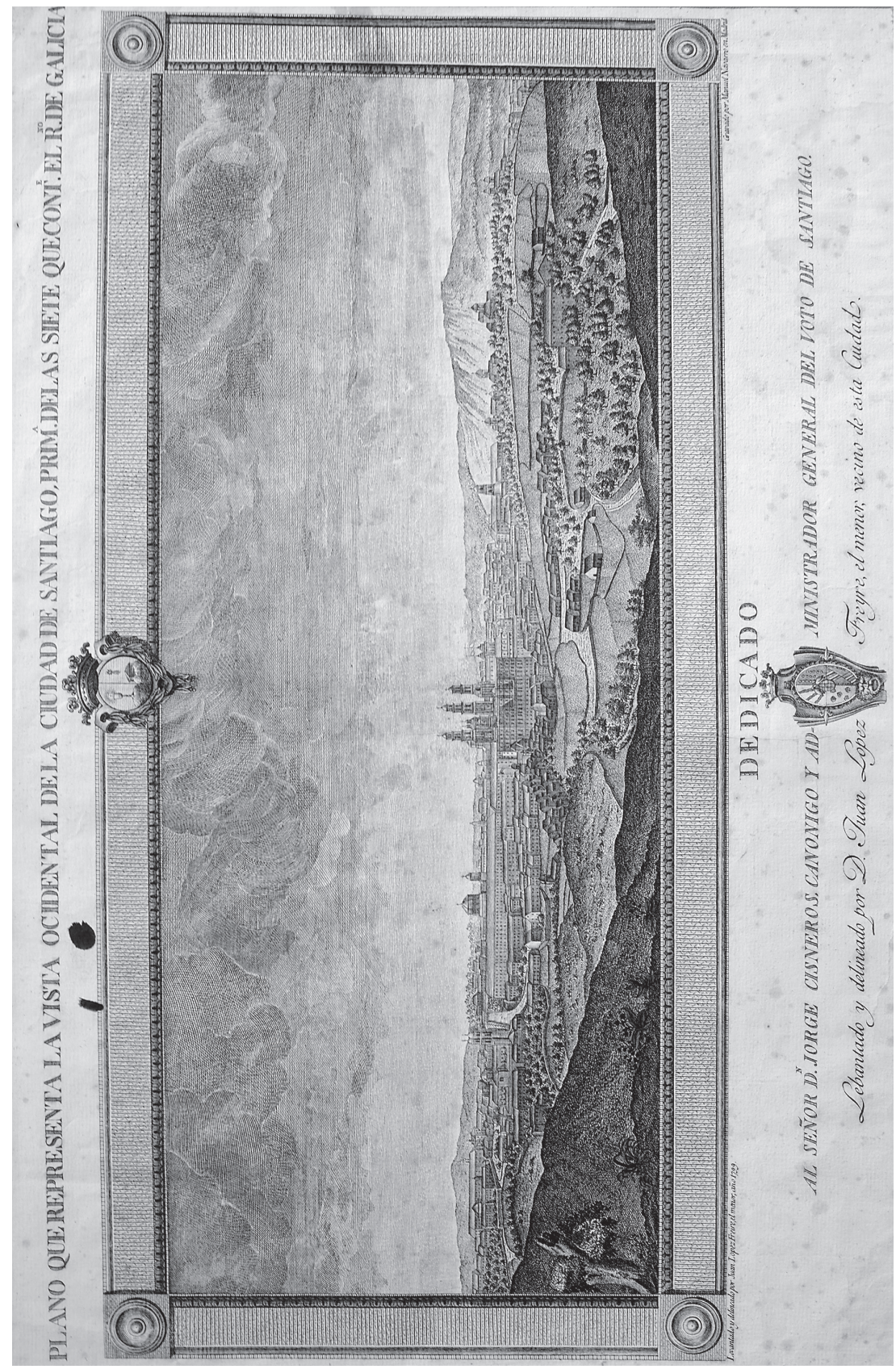

Fig. 3

Juan López Freire, hijo: vista de la ciudad de Santiago en 1799. 
VOTO DE SANTIAGO. Lebantado y delineado por D. Juan López Freyre, el menor, vecino de esta Ciudad". Además, presenta dos escudos, uno en el marco de la vista, que corresponde al nuevo escudo de la ciudad ${ }^{7}$, y otro al pie que corresponde al canónigo a quien se dedica ${ }^{8}$, administrador del Voto de Granada ${ }^{9}$.

Así pues, al tal Juan López Freire “el menor” debemos la primera corografía compostelana realizada por un artista local, llevada a la estampa en la citada fecha de 1799 por Manuel Navarro, conocido grabador madrileño ${ }^{10}$. Se trata del hijo del arquitecto del mismo nombre, autor de numerosas casas de la ciudad, conocido por dirigir las obras de construcción de la actual Facultad de Geografía e Historia, el Convento de la Enseñanza y la Capilla de Ánimas, entre otras ${ }^{11}$. Lamentablemente, apenas sabemos nada más salvo que nació en Compostela en 1774, que estudió arquitectura en la Academia de San Fernando, que hizo una traza para la capilla de la Pastoriza y que le corresponde la autoría de la vista que aquí analizamos ${ }^{12}$. Un dato interesante que demuestra sus cualidades para el dibujo es que, tras inscribirse en 1795 en el concurso de la Academia, en el

\footnotetext{
7 Se trata de escudo partido. En el primero figuran las armas del Reino de Galicia para señalar su condición de capital del mismo, un cáliz sumado de una hostia. En el segundo aparecen propiamente las antiguas armas de la ciudad, una nube sumada de la urna del sepulcro del Apóstol Santiago, surmontada de una estrella. Al timbre, Corona Real abierta. Cfr. J. Bugallal y Vela, "Armas de la M.N. y M.L. Ciudad de Santiago de Compostela", Gran Enciclopedia Gallega, Santiago-Gijón, 1974, vol. 28, págs. 57-59.

8 Cfr. L. Fariña Couto, O libro da heráldica galega, Fundación Pedro Barrié de la Maza, 2001, págs. 102 y 306.

9 De sus problemas con el arzobispo Malvar para ocupar y desempeñar el cargo, en los años anteriores a la fecha del plano, da noticias A. López Ferreiro (Historia de la Santa A.M. Iglesia de Santiago de Compostela, vol. XI, Santiago, 1911, págs. 47, 52 y 62-68).

${ }^{10}$ La mayoría de las estampas que se le conocen son de contenido religioso como se puede comprobar en el catálogo on line de la Biblioteca Nacional. Véanse más ejemplos en J. CARreTE PArrondo, J. Fernández Delgado y J. Vega González, "Catálogo", en Estampas. Cinco Siglos de Imagen Impresa, catálogo de exposición, Madrid, 1981, grabs. núms. 45 y 747; J. CARRETE PARRONDO et al., Catálogo del Gabinete de Estampas del Museo Municipal de Madrid, t. I, Madrid, 1985, págs. 33, 308 y 311-312; J. Carrete Parrondo, "El grabado en el siglo XVIII. Triunfo de la estampa ilustrada", Summa Artis, El Grabado en España (siglos XV al XVIII), vol. XXXI, Madrid, 1987, pág. 430; J. Carrete Parrondo, Catálogo general de la Calcografía Nacional, Madrid, 1987, 42; E. Pernoud, "Le épreuves de sainte Thérèse: la collection de Manuel Navarro", Nouvelles de l'estampe, 1994, págs. 23-25.

${ }^{11}$ Para su biografía y obra todavía es válido J. Couselo Bouzas, Galicia Artística en el siglo

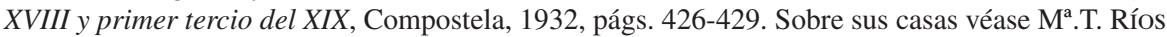
Miramontes, La arquitectura civil compostelana en el siglo XVIII, Santiago, 2000, págs. 33-48. Sobre la calidad de las planimetrías de su autoría véanse las publicadas en A. VIGo Trasancos (dir.), J. Sánchez García y M. TAín GuZmán (coords.), Galicia y el siglo XVIII. Planos y dibujos de arquitectura y urbanismo (1701-1800), Fundación Pedro Barrié de la Maza, 2011, págs. 764, 783, 796, 801, 813, 818, 826, 890 y 894-897.

${ }^{12}$ Cfr. M. Murguía, El arte en Santiago durante el siglo XVIII y noticia de los artistas que florecieron en dicha ciudad y centuria, Madrid, 1884, 219; J. Couselo BouzAs, op. cit., pág. 430.
} 


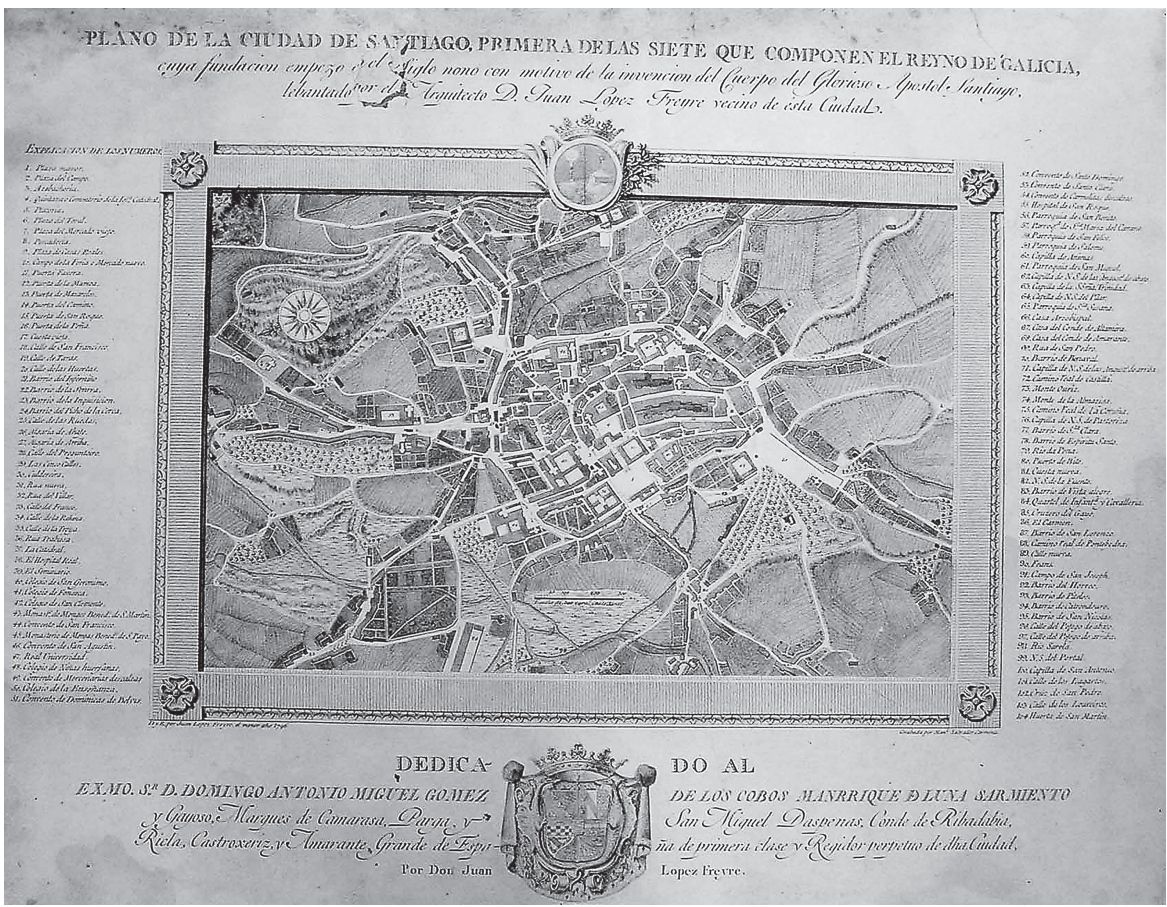

Fig. 4

Juan López Freire, hijo: plano de la ciudad de Santiago en 1796.

apartado de Arquitectura (Tercera Clase), quedó de segundo, recibiendo el 13 de julio de 1796 una medalla de plata de tres onzas de manos de Manuel Godoy, primer ministro de Carlos IV. La prueba que superó tuvo dos partes. La primera consistió en "delinear en grande el capitel y ornamento corintio, según Vignola, demostrando en planta las partes de que consta, con cornisamento, debiendo ser el módulo de quatro dedos" (prueba de pensado), dibujos que hubo de entregar a la Academia unos días antes, entre el 7 y 9 de julio. En la segunda tuvo que dibujar en el plazo de dos horas el 9 de julio en las instalaciones de la institución académica "el pedestal, basa é imposta del orden dórico" (prueba de repente) ${ }^{13}$.

La corografía parece hacer pareja con la conocida primera planimetría impresa de la ciudad, firmada por el mismo autor en 1796 y llevada a la estampa

${ }^{13}$ Cfr. Distribución de los premios concedidos por el rey nuestro señor á los discípulos de las tres nobles artes, hecha por la Real Academia de San Fernando en la Junta Pública de 13 de julio de 1796, Madrid, s.d. Se conserva la documentación de la inscripción del artista al concurso, por cierto fuera de plazo, en los archivos de la Academia (signatura 2-3-3 y 2-3-3bis). Documentación facilitada por Antonio Bonet Correa y Esperanza Navarrete. 
por Manuel Salvador Carmona, uno de los mejores grabadores de su tiempo, posiblemente también en Madrid ${ }^{14}$ (fig. 4). Lo indica el hecho de que el dibujo también se dispone dentro de un grueso marco rectangular, con adornos en los ángulos, la distribución similar de escudos y leyendas, así como la presencia de otra dedicatoria a una autoridad, en este caso a Domingo Gayoso de los Cobos, XI Marqués de Camarasa y Regidor perpetuo de Santiago, entre otros títulos ${ }^{15}$. La planta es muy veraz, presentando escala y ciento cuatro textos que identifican mediante números los edificios más significativos, las antiguas puertas de la muralla, las calles y los barrios de la ciudad. Nos muestra, además, como conserva las plazas que rodean a la catedral, regularizadas en los siglos XVII y XVIII, y el entramado de calles y manzanas de casas todavía fundamentalmente medievales. El detalle alcanza a señalar los soportales de las calles y los claustros de los edificios, el posteado de las lonjas como el del Hospital Real, las escaleras urbanas como las de la Quintana, Platerías, Azabachería o la iglesia de San Marín Pinario, las fuentes como la de la Plaza de Cervantes o del Colegio de San Clemente, así como las plantas de las iglesias y de la catedral, esta última con los pilares de sus naves, el cierre de la sillería de coro y las escaleras del Obradoiro. También, y ésta es la gran novedad con respecto a testimonios anteriores, como ya se ha demolido parte de su recinto amurallado, sustituido por nuevas manzanas de viviendas, que todavía se mantienen en la actualidad, al haber sido vendido por parcelas por el ayuntamiento. Igualmente, se constata como tal derribo ha permitido la expansión del caserío por el antiguo camino que rodeaba el perímetro de la muralla, ahora transformado definitivamente en calles, por ejemplo el tramo de la Costa Vella o la Rúa das Carretas, y el crecimiento de los antiguos barrios extramuros, como el de Santa Clara-Espíritu Santo o el de la Senra-Carreira do Conde. Además, recoge el parcelario de tierras cultivadas, pastos y bosques que rodeaban Compostela en ese momento y que sustentaban en parte a su crecida población. Del mismo modo se consignan sus accidentes topográficos como el monte de la Almáciga, el río Sarela y regatos como el Corvo o el Cancelón, así como caminos reales y rueiros. Todos estos aspectos analíticos apuntan a la autoría de un arquitecto y son fundamentales para la correcta lectura de la vista de 1799, como veremos a continuación, a la que podemos considerar como un alzado del plano, el retrato de su rostro occidental.

\footnotetext{
${ }^{14}$ Cfr. G. Méndez Martínez, Cartografía antigua de Galicia, Vigo, 1994, 195. Véase buena reproducción en Ma.L. Sobrino y P. de Llano (coords.), Cartografía básica da cidade de Santiago de Compostela, Santiago, 1990. Sobre el grabador véase J. Carrete Parrondo, "Manuel Salvador Carmona", Summa Artis, op. cit., vol. XXXI, págs. 484-508.

${ }^{15}$ Un ejemplar del plano fue regalado por el citado Gayoso de los Cobos, con un enmarque dorado y vidrio, al Ayuntamiento para ser expuesto en el Salón de Plenos, según acta consistorial del 27 de enero de 1798; Archivo Histórico Universitario de Santiago, AM 282, Libro de Actas Consistoriales, fol. 45 r.
} 
Desconocemos los motivos exactos de su origen ${ }^{16}$. No obstante, es evidente que responde a la nueva moda ilustrada, arraigada en Europa, de contar con representaciones impresas de ciudades y monumentos españoles ${ }^{17}$. A los alumnos de la Academia de San Fernando corresponden los primeros grabados de este tipo, como por ejemplo la Vista de la Cárcel de Corte (1756), la Vista del Puente de Toledo (1756), la Vista del Palacio de Aranjuez (1757), la Vista del Acueducto de Segovia (1757) de Hermenegildo Víctor Ugarte, entre otros. Pero es la Real Calcografía a finales de siglo, con sus colecciones de estampas como la de Vistas de los puertos de mar de España (1782-1785), y, sobre todo, las vistas de ciudades que ilustran libros como Atlante Español o descripción general de todo el Reino de España (1784) o la Colección de estampas de fachadas, o vistas de palacios, edificios y monumentos antiguos y modernos (1789), ambos con grabados de Juan Fernando Palomino, las que acabaron por popularizar la nueva temática ${ }^{18}$.

Al igual que en las vistas compostelanas anteriores, también López Freire buscó un promontorio elevado para dibujar, pero con la aspiración de representar una imagen completamente diferente a las ya citadas. En efecto, buena parte de la ciudad, desde Pinario al Colegio de Fonseca, así como los barrios del norte y del oeste, como Santa Clara, San Francisco, Hortas, Pombal, Carmen de Abaixo, Santa Susana, Poza de Bar y San Lourenzo, fueron dibujados desde la aldea de Sarela de Abaixo, mirador excepcional sito en las estribaciones del Monte del Pedroso, sobre el valle del Sarela, desde el que hay un amplísimo ángulo de visión de la urbe y sus principales monumentos, con una espectacular vista frontal de la Catedral (contrastar figs. 3 y 5). Lamentablemente, desde dicho lugar no se alcanzan a ver las manzanas del caserío y edificios nobles del sur, el área urbana más extensa. El motivo es que permanecen parcialmente ocultos detrás del monte de Santa Susana y su vegetación, destacando únicamente parte del inmueble de la antigua sede de la Universidad, hoy Facultad de Geografía e Historia, que, debido a la perspectiva, da la impresión de estar pegado a su arboleda. Ello podría explicar la peculiar ubicación del edificio en el grabado, el cual, junto a varios campanarios y/o cimborrios y linternas que asoman sobre los árboles, pueden observarse tal cual desde un monte vecino a dicha aldea, llamado Pereiros por sus vecinos, de 285 metros de altura, sito al norte de la

\footnotetext{
${ }^{16}$ Obviamente no está relacionado con el encargo de un mapa topográfico de la ciudad en la reunión del consistorio del 20 de abril de 1799 para conocer el estado del parcelario de la ciudad y del trazado de sus calles, así como de un segundo con un proyecto para la regularización del trazado viario; AHUS, AM 284, Libro de Actas Consistoriales, fol. 251r.

${ }^{17}$ Cfr. C. de Seta, Ritratti di città. Dal Rinascimento al secolo XVIII, Torino, 2011, págs. 112 y ss.

${ }^{18}$ Cfr. J. Carrete Parrondo, "El grabado en el siglo XVIII. Triunfo de la estampa ilustrada", Summa Artis, op. cit., vol. XXXI, págs. 443-444, 525-558 y 632.
} 


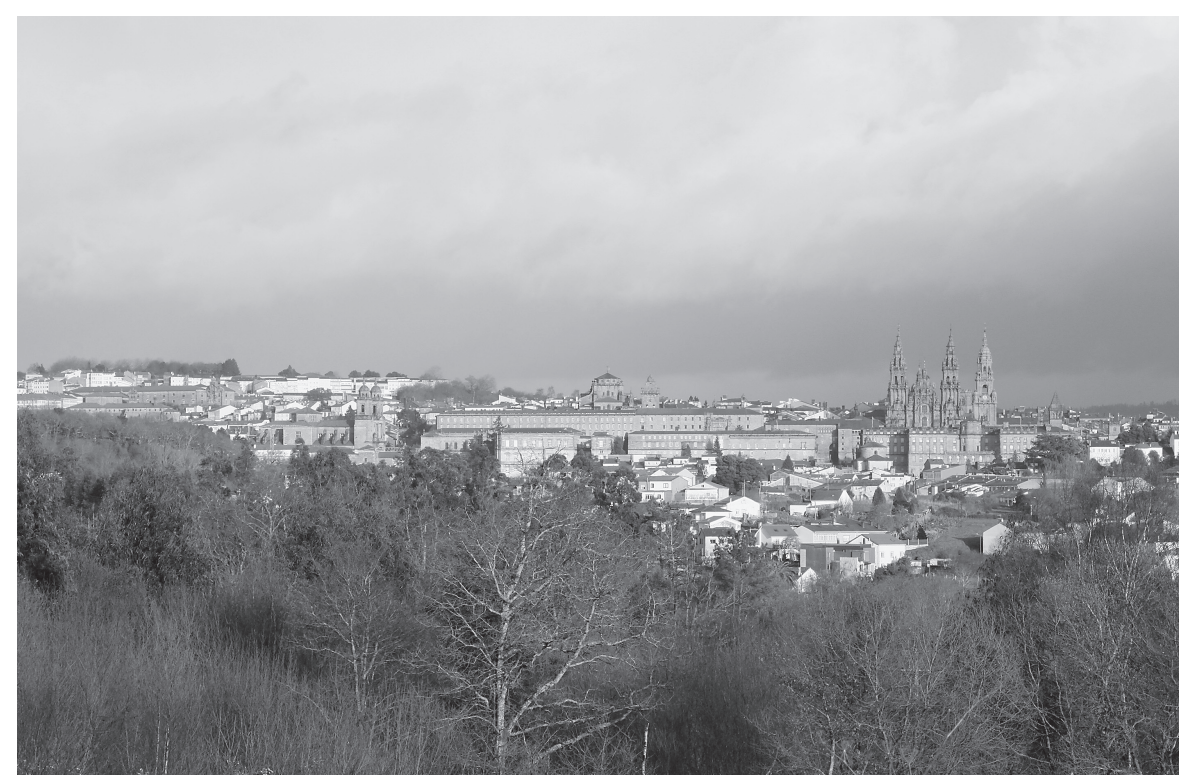

Fig. 5

Vista actual de la ciudad desde Sarela de Abaixo.

misma, pegado a la vera del camino de Santa María de Figueiras, hoy carretera, en dirección a Bar de Arriba (contrastar figs. 3 y 6 y véase estudio de cuencas visuales de Ramón Blanco en las figs. 7 y 8). Por la inclinación de las sombras de la fachada trasera del Palacio de Rajoy se deduce que el artista tomó sus notas a una hora avanzada de la mañana, para las cuales, sospecho, se ayudó de algún tipo de lente que le permitiese acercar y ampliar la imagen de los edificios. A partir de estos primeros dibujos preparatorios, como antes habían hecho los autores de las vistas de 1666 y 1669, "compuso" en la tranquilidad de su estudio la representación definitiva.

La imagen resultante constituye un "perfil natural" según la clasificación tipológica de corografías urbanas de Cesare da $\operatorname{Seta}^{19} \mathrm{y}$, para las españolas, de Fernando Marías ${ }^{20}$. En efecto, la orografía del terreno sobre el que se asienta la

\footnotetext{
${ }^{19}$ Cfr. C. de SETA, Ritratti di città..., op. cit., págs. 30-31

${ }^{20}$ Cfr. F. Marías, "Tipología delle immagini delle città spagnole", en C. de Seta (a cura di), Città d'Europa. Iconografia e vedutismo dal XV al XVIII secolo, Italia, 1996, págs. 101-117, especialmente 111; F. MARías, "Imágenes de ciudades españolas: de las convenciones cartográficas a la corografía urbana", en F. Marías y F. Pereda (edits.), El Atlas del Rey Planeta. La Descripción de España y de las costas y puertos de sus reinos de Pedro Texeira (1634), Madrid, 2002, págs. 99-116, especialmente 104.
} 


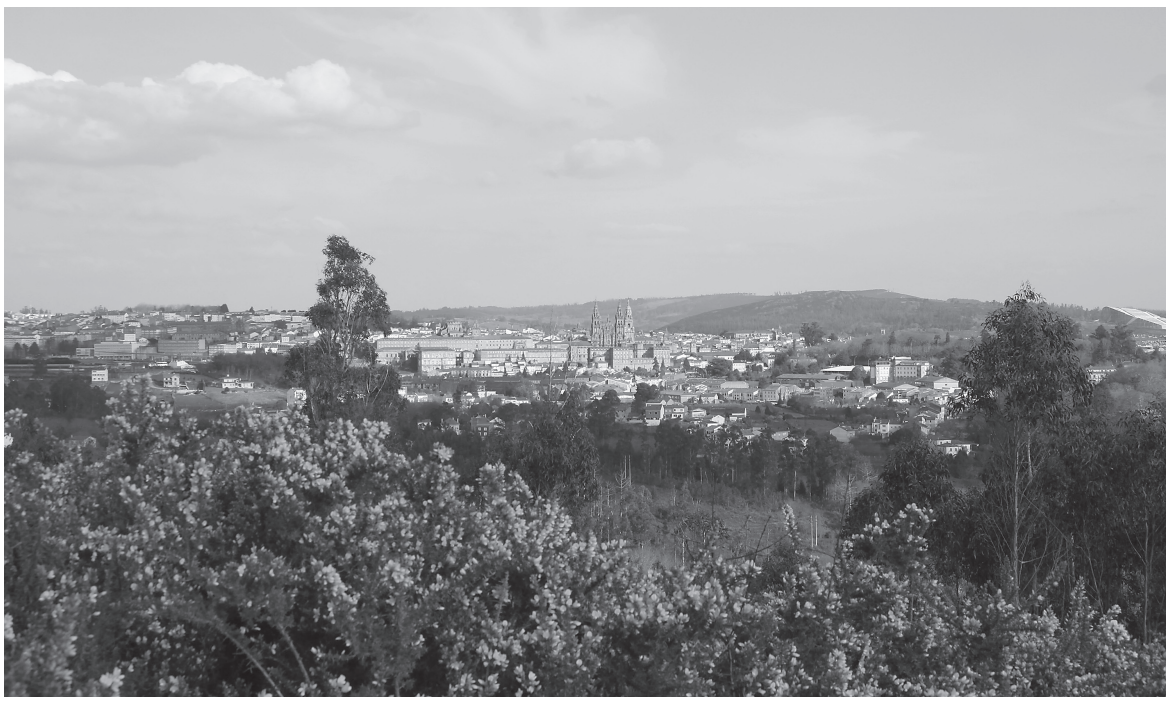

Fig. 6

Vista actual de la ciudad desde Pereiros, montículo de 285 metros en Sarela de Abaixo.

ciudad, un monte entre los valles del Sar y el Sarela, este último grosso modo fielmente representado en el grabado, explica la superposición escalonada en sentido ascendente de los edificios de la zona occidental, aplicándose, aunque no de manera estricta, las leyes de la perspectiva para la disminución correcta de los tamaños de las edificaciones. Ello no evita que los inmuebles de la parte delantera oculten a buena parte de los que quedan detrás, salvo campanarios, cimborrios y peinetas. También justifica que las zonas oriental y meridional de la urbe, salvo algunas alturas, no figuren en la corografía, pues no se pueden ver desde donde han sido tomados los bocetos, siendo imposible por lo tanto reflejar una visión global de Compostela.

En primer término se representan las estribaciones del Monte del Pedroso a lo largo del valle del Sarela, llegándose a distinguir el curso del río con hileras de árboles de ribera. El tronco roto y viejo del ángulo izquierdo, un roble quizás, indicaría la proximidad de zonas de arboleda, siendo las actuales, en su mayoría plantaciones nuevas. En el horizonte, los árboles que asoman por encima de la Costa Vella corresponden a los del convento de Santo Domingo de Bonaval y al Monte de la Almáciga, zonas muy visibles desde Sarela de Abaixo (contrastar figs. 3 y 5). En cambio, por encima del Monte de Santa Susana se eleva el Monte do Viso y, más a la derecha, el Gaiás, y de fondo otras estribaciones más lejanas, que sólo se pueden ver desde Pereiros, el citado montículo vecino a la aldea (contrastar figs. 3, 6, 7 y 8). 
Cuencas visuales y lineas visuales sobre algunos de los edificios identificados
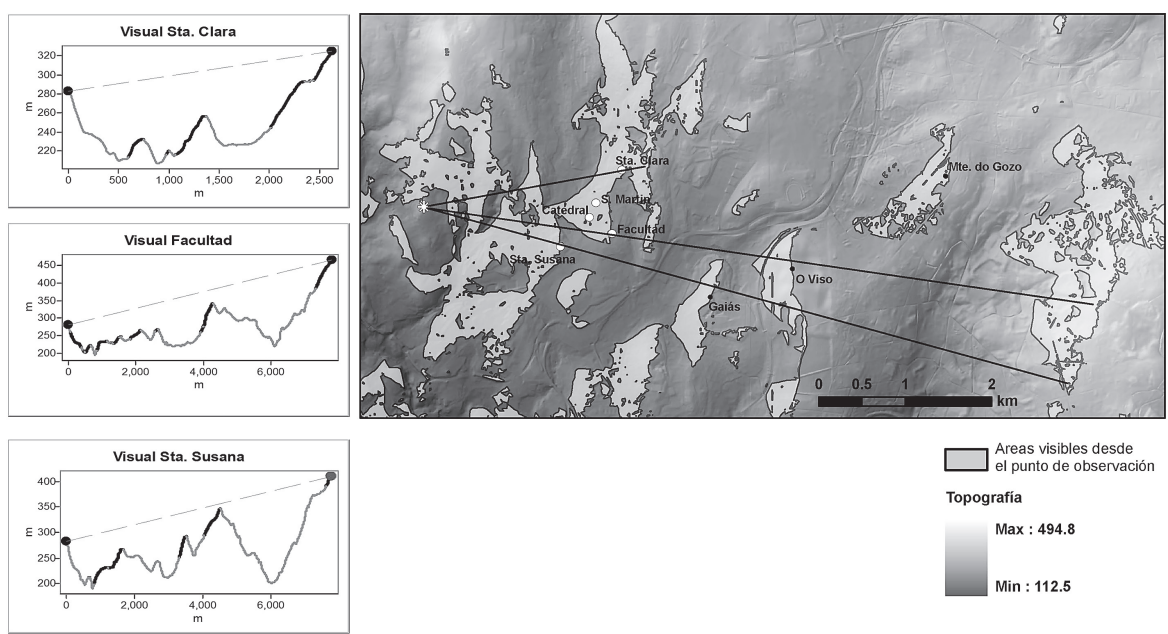

- Visible

Fig. 7

Ramón Blanco: estudio de las cuencas visuales de la ciudad de Santiago desde Pereiros, montículo de 285 metros en Sarela de Abaixo, donde se tomaron notas para la realización de la vista.

Los dibujos preparatorios no se han conservado, pero sospecho que no debían diferir mucho de los realizados por Anton van den Wyngaerde, cuyas corografías de ciudades españolas resultan en general de la unión de distintos bocetos preparatorios tomados directamente del natural desde diferentes puntos (bocetos de localización del enclave, de sectores de la ciudad y de detalles de edificios), muchos de los cuales sí han llegado hasta nuestros días ${ }^{21}$. Tal procedimiento explicaría los errores, simplificaciones e ingenuismos que se detectan en los inmuebles compostelanos representados por López Freire, como por ejemplo la sintetización de las torres de la catedral o el cimborrio de Pinario. Además, pese a la inclinación natural del terreno no hay una representación minuciosa del tejido urbano ni de su trama viaria, sino una evocación de ambos, de mayor o menor realismo, plasmando la impresión que produjo en el artista. La perspectiva de los edificios tampoco es siempre acertada como se puede ver en las torres de la fachada de San Francisco. Así se explica que Murguía acusase inmerecidamente a la vista como "de escaso mérito" 22 . No obstante todo lo dicho, el autor ha

${ }^{21}$ Cfr. R.L. Kagan (dir.), Ciudades del Siglo de Oro. Las Vistas Españolas de Anton Van den Wyngaerde, Madrid, 1986.

${ }_{22}$ Cfr. M. Murguía, El arte en Santiago..., op. cit., pág. 219. 

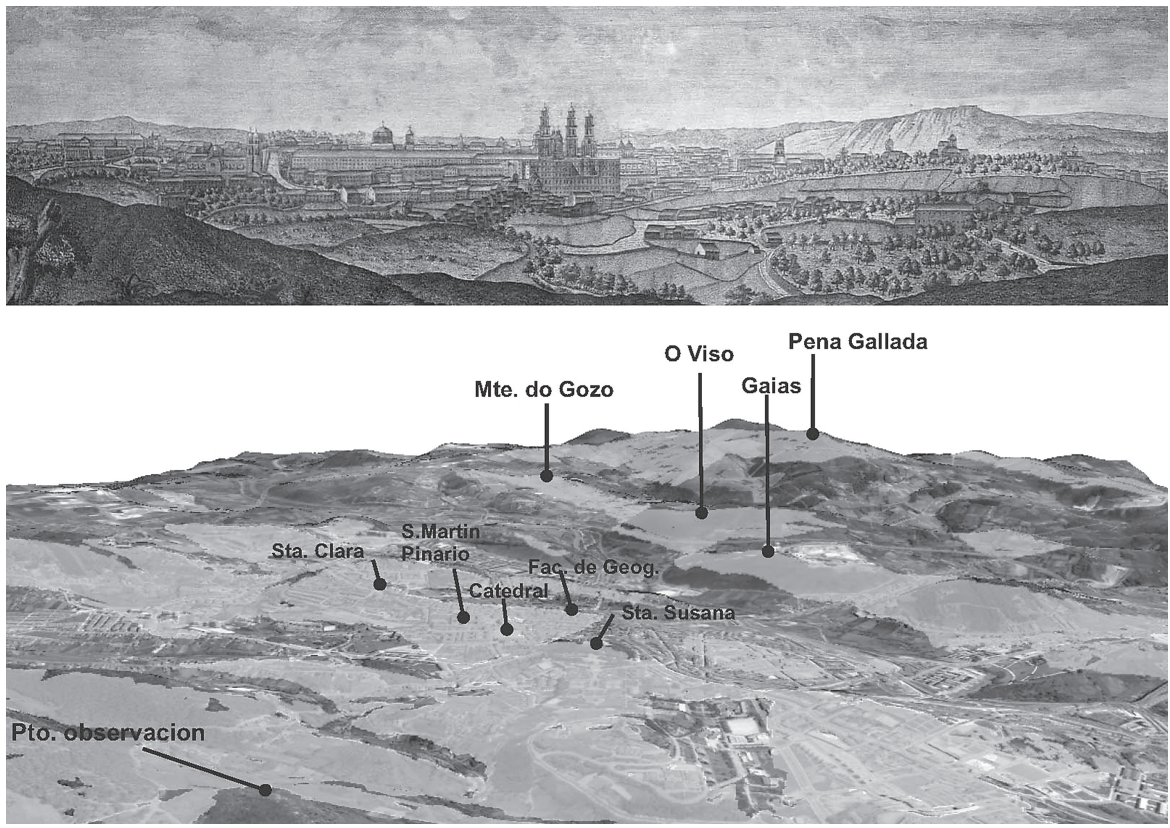

Fig. 8

Ramón Blanco: estudio de las cuencas visuales de la ciudad de Santiago desde Pereiros, montículo de 285 metros en Sarela de Abaixo donde se tomaron notas para la realización de la vista.

logrado mostrar una topografía urbana coherente y reconocible, ofreciendo un estudio físico de la localidad y la ilusión de una urbe abarcable con la mirada, poblada de monumentos de representación fiable por el dibujo de sus volúmenes arquitectónicos.

Sorprende que sólo hayamos localizado un ejemplar del grabado, expuesto enmarcado en el Museo de Pontevedra. En 1860-1861 el Instituto de Enseñanza Media de Santiago contaba con uno también enmarcado regalo del director del centro $^{23}$ y en 1932 Couselo Bouzas afirma que en su tiempo algunos particulares también lo poseían ${ }^{24}$. Varios autores en los últimos años lo han utilizado a modo de ilustración en sus trabajos, sin estudiarlo ni mencionar su origen ${ }^{25}$. Estoy convencido de que a raíz de la publicación de este análisis aparecerán otros.

${ }^{23}$ Cfr. H. Capel, M. Araya, M. Brunet y otros, Ciencia para la burguesía, Barcelona, 1983, pág. 119.

${ }^{24}$ Cfr. J. Couselo Bouzas, op. cit., pág. 430.

${ }^{25}$ Por ejemplo en P. Costa Buján y J. Morenas Aydillo, Santiago de Compostela 1850-1950, Santiago, 1989, 44 y X.X. Pazos Pérez, Chemineas en Compostela, s.l., 1999, pág. 93. 


\section{LA PRIMERA VISTA DE LA CIUDAD MONUMENTAL}

López Freire es un arquitecto no un pintor paisajista. Ello explica que para confeccionar su "imagen construida" de la ciudad, bajo el típico cielo de tormenta que tal vez acompañó al artista durante los días que elaboró sus bocetos en el campo, haya elegido la fachada arquitectónica más monumental, aquella que le permite representar aquellos edificios que más dignifican a Compostela, particularmente los que rodean la Plaza del Obradoiro, resaltando su magnitud $\mathrm{y}$ arquitectura.

La urbe ya no presenta el aspecto medieval de las vistas de 1666 y 1669 . Bien al contrario, el proceso de renovación en ellas recogido culmina ahora con las intervenciones de la segunda mitad del siglo XVII y del siglo XVIII, de la mano de arquitectos como Domingo de Andrade, Fernando de Casas, Lucas Ferro Caaveiro, Clemente Fernández Sarela, Simón Rodríguez y Charles Lemaur, entre otros, que cambian radicalmente su fisonomía, construyendo nuevos decorados y escenografías, que la barroquizan y magnifican ${ }^{26}$. La vieja muralla del obispo Cresconio, antiguo símbolo del poder, ha prácticamente desaparecido en el grabado. No obstante, se puede seguir su trazado por la disposición del caserío, particularmente de las nuevas manzanas de casas que habían desbordado la cerca y colocado paralelamente al muro, por ejemplo en la Rúa das Carretas (entonces llamada Calle de Tarás), y de algunas calles: me refiero a Costa Vella y a Costa de San Francisco. Aunque la zona no figura representada con claridad, la primera linda con el nuevo cierre de la huerta de San Martín Pinario, que sustituyó a la citada muralla hacia 1733, reutilizando sus piedras ${ }^{27}$, y la segunda con el cierre de la huerta del Hospital Real, que desconocemos si se trata todavía de la muralla (contrastar como se dispone el cierre en las figs. 3 y 4). Además, también se conservaban entonces algunos segmentos escondidos detrás de las casas y de los edificios dibujados, como por ejemplo Puerta Faxeira, demolida en $1830^{28}$, o

\footnotetext{
${ }^{26}$ Cfr. A. Vigo Trasancos, "Santiago 1600-1770. La metamorfosis barroca de un santuario de peregrinación", en C. Martí Arís (ed.), Santiago de Compostela: la ciudad histórica como presente, Santiago, 1995, 98-107. Para conocer cómo era la ciudad en los años del grabado véase $\mathrm{F}$. Singul, La Ciudad de las Luces. Arquitectura y urbanismo en Santiago de Compostela durante la Ilustración, Santiago, 2001. Para una valoración global de cada una de las intervenciones véase X.M. García Iglesias (dir.), Santiago de Compostela, Patrimonio Histórico Gallego, Ciudades, Laracha, 1993. Sobre la evolución de la muralla, las principales calles y las plazas que rodean la catedral entre los siglos XVI y XVIII véase A.A. Rosende VALDÉs, Una historia urbana: Compostela, 1595-1780, Santiago, 2004. Tal esplendor monumental se corresponde con una época de auge demográfico, social, económico y cultural estudiado en E. Portela Silva (coord.), Historia de la ciudad de Santiago de Compostela, Santiago, 2003, págs. 223-429.

${ }^{27}$ Cfr. A.A. Rosende Valdés, Una historia urbana..., op. cit., págs. 80-81.

${ }^{28}$ Ibídem, págs. 59-61.
} 
el torreón-mirador de la lonja del Hospital Real que se ha mantenido, reducido, hasta nuestros días ${ }^{29}$.

Dado el ángulo de la panorámica, López Freire no logra reflejar la intrincada red de calles y plazas de la ciudad histórica, completamente desdibujada entre el apretado caserío, intuyéndose algunos vacíos como la Plaza del Obradoiro y las calles de San Francisco y la desembocadura del Franco, estas últimas por las líneas de los tejados de los edificios. Dado que la manzana del Hospital Real linda al este con la Rúa de San Francisco y al oeste con la Rúa das Carretas, nos falta la manzana de la Rúa do Val de Deus, aunque los tejadillos de tres casas podrían corresponderle. La Rúa das Carretas presenta la línea de casas que sigue al inmueble del Hospital y la vertiente contraria con sus huertas, quedando en medio una manzana inventada (contrastar como se disponen esas manzanas en las figs. 3 y 4). Más ricos son los datos de la red de calles y caminos en los barrios y campos de las afueras, representándose con claridad las citadas Costa Vella y Costa de San Francisco, hasta unirse con la Rúa das Carretas, en un tramo arbolado, e intuyéndose otra vez por el trazado del caserío, con mayor o menor rigor, calles como la de San Roque, Castiñeiros, Hortas, Carmen de Abaixo, Pombal, Trinidade, San Clemente, Avenida Rodrigo de Padrón, Poza de Bar y San Lourenzo (contrastar el trazado de las calles en las figs. 3 y 4).

La gran cantidad de viviendas tanto en la ciudad, como ya he dicho muy pegadas unas a otras, como en los antiguos barrios que quedan extramuros, en este caso y como hemos visto con casas en hilera al borde de los caminos, en eje con las antiguas puertas de la ciudad, testimonian el crecimiento de la población de Compostela, entonces, tras A Coruña, la más poblada del reino ${ }^{30}$. Por la documentación y antiguas descripciones sabemos que el caserío popular sigue presentando cierta impronta medieval, por sus soportales y voladizos, estando muchas casas construidas todavía de madera con algunos elementos de piedra. En cambio, canónigos, nobleza, hidalguía y burguesía viven en casonas de piedra, algunas de gran empaque y con patio central porticado, habiendo debido de desaparecer la mayoría de las antiguas casas-torre que figuran en Baldi, o al menos no se representan, con la excepción del Palacio Arzobispal ${ }^{31}$ (contrastar el caserío de las figs. 2 y 3). Por desgracia en el grabado no se logra identificar

\footnotetext{
${ }^{29}$ Sobre su trazado y los restos véase M. González Méndez y J. Luaces Anca, Santiago de Compostela. A cerca da cidade, Santiago, 2009, págs. 19 y 26-30.

${ }^{30}$ En 1787 contaba con 15.582 habitantes; cfr. P. SaAvedra Fernández, "El dinamismo socioeconómico del principal núcleo urbano de Galicia”, en E. Portela Silva, op. cit., págs. 239-240; E. Martínez RodríGuez, "Demografía urbana de Antiguo Régimen en Galicia: la ciudad de Santiago de Compostela", Obradoiro de Historia Moderna, 13 (2004), págs. 255-276.

${ }^{31}$ El caserío compostelano sufrirá una radical renovación en el siglo XIX y primeros años del XX, conservándose hoy sólo unos pocos ejemplos antiguos representativos; cfr. P. Costa BuJÁN y J. Morenas Aydillo, op. cit.
} 
ninguna residencia concreta, salvo el palacio mencionado del que luego se tratará. En algunos barrios, como San Lourenzo, y en el rural, por ejemplo en el valle del Sarela, predominan las casas terrenas. Muchos inmuebles cuentan con huertas, particularmente las del extrarradio, como indican algunos cierres de piedra de Carretas, Hortas, Poza de Bar y San Lourenzo, donde los compostelanos venían cultivando frutales, verduras, hortalizas, etc., y criaban algunos animales, desde la Edad Media ${ }^{32}$. Sorprendentemente, en el conjunto de la vista se ha soslayado por completo una de las señas de identidad de la arquitectura doméstica compostelana, la chimenea, que sí figura en Baldi, y de las que aquí no aparece dibujado un solo ejemplar ${ }^{33}$ (contrastar figs. 2 y 3). Dado el tamaño del grabado y su esquematismo, no se puede valorar hasta qué punto se empezaban a aplicar las nuevas Ordenanzas de Policía de la Ciudad de Santiago de $1780^{34}$ que obligaba a la destrucción de voladizos y soportales y la regularización del trazado de las calles; la construcción de viviendas en línea recta, uniformes en altura y tamaño y con disposición simétrica de los vanos; el empedrado de las calles y las plazas; así como la canalización de las aguas de la lluvia y de las vertidas por el caserío ${ }^{35}$.

Dentro de la ciudad, entorno a las plazas del Obradoiro, Platerías, Quintana y Azabachería que rodean la catedral, se distribuyen sus principales edificios monumentales. Así, de izquierda a derecha, distinguimos los siguientes: el monasterio de San Martín Pinario, el Hospital Real, el Palacio de Rajoy, el Palacio Arzobispal, la Catedral, el Palacio Capitular, la Torre de la Vela, la Torre del Tesoro, el Colegio de San Jerónimo, el Colegio de Fonseca y el Monasterio de San Pelayo. La mole del amplio complejo monacal benedictino de Pinario destaca sobremanera, particularmente el bloque de celdas occidental, del que se representan sus últimas tres hileras de ventanas, manifestando el poder de la abadía y su amplia población de monjes, setenta y nueve en $1800^{36}$, siendo Antonio Llorente su abad en la fecha del grabado ${ }^{37}$ (contrastar figs. 3 y 5). En la vista no se diferencia la fachada correspondiente al Claustro de las Oficinas, construido

\footnotetext{
${ }_{32}$ Cfr. J. Armas Castro, "El afianzamiento de la realidad urbana después del año mil”, en E. Portela Silva, op. cit., págs. 94-95.

${ }^{33}$ Cfr. X.X. Pazos Pérez, op. cit.

${ }^{34}$ Impresas todavía en 1799, fecha del grabado.

${ }^{35}$ Cfr. F. Singul, op. cit., págs. 103-123; texto de las ordenanzas en 383-388. Sobre esta cuestión véanse también $\mathrm{M}^{\mathrm{a}}$. del S. Ortega Romero, "Aspectos urbanísticos del barroco compostelano: voladizos y soportales", Revista de la Universidad de Complutense, 22, núm. 85 (1973), págs. 163 187; A.A. Rosende VALDÉs, Una historia urbana..., op. cit., 87-172.

${ }^{36}$ Cfr. O. Rey Castelao, "Cistercienses y benedictinos en la Galicia Moderna: evolución numérica y análisis social", Actas do Congreso Internacional sobre S. Bernardo e o Císter en Galicia e Portugal, Oseira 17- 20 de outubro de 1991, vol. 1, Ourense, 1992, pág. 312.

${ }^{37}$ Cfr. J.R. Barreiro Fernández, "Abadologio del Monasterio benedictino de San Martín Pinario en Santiago de Compostela (1607-1835)”, Studia Monástica, 7, núm. 1 (1965), pág. 182.
} 
en la segunda mitad del siglo XVII, de autoría y fases constructivas todavía discutidas $^{38}$, de su prolongación en dirección norte, hacia San Francisco, lindando con la Rúa do Val de Deus, con una cronología y distribución de vanos diferente. En efecto, del segundo se conserva la traza con la rúbrica de Fray Gabriel de las Casas en el Archivo Histórico Diocesano, fechable de hacia 1705-1707³9, y fue construido en los años siguientes, durante el gobierno del abad Gregorio de Haro $(1709-1713)^{40}$.

Sobre ese edificio asoman el que parece el testero de la cabecera de la iglesia, el remate poligonal de la torre de la cúpula del crucero y la espadaña del monasterio. El citado muro de la iglesia, de enorme altura, se atribuye a Mateo López y fue construido a partir de 1598, no presentando ningún rasgo particular ${ }^{41}$. Más interesante es el cimborrio atribuido a Bartolomé Fernández Lechuga y construido en las décadas de 1630 y $1640^{42}$. De él se distingue el cuerpo dodecagonal con los doce vanos que permiten la entrada de luz separados por pilastras, la cubierta de teja del país y la vara metálica levantada en el vértice. En cambio, la arquitectura de la espadaña barroca del cenobio, fechada en 1675, se simplifica al máximo. El primer cuerpo, acaso ya tapiado como en la actualidad y por haber

\footnotetext{
${ }^{38}$ Para A. Goy Diz, "Nuevas puntualizaciones sobre el llamado Claustro de las Oficinas del monasterio de San Martín Pinario", en M. ${ }^{a}$ del C. Folgar de la Calle, A. Goy Diz y J.M. López Vázquez (coords.), Memoria Artis. Studia in memoriam Ma ${ }^{a}$. Dolores Vila Jato, Galicia, 2003, págs. 351-370, las trazas de los dos primeros pisos corresponden a José de la Peña de Toro y datarían de hacia 1660 , mientras los dos últimos lo serían de 1677, según informa la fecha grabada en la panda meridional, dudando sobre la autoría entre Diego de Romay y Fray Tomás Alonso. En cambio, S. Vicente López, Vega y Verdugo, Peña de Toro y la introducción del barroco en Compostela, Santiago, 2012, págs. 68-70, atribuye la traza de todo el edificio a Fernández Lechuga y fija su cronología entre 1665 y 1681.

39 Véase buena reproducción en A. Vigo Trasancos, J. Sánchez García y M. Taín Guzmán, op. cit., 67 y dib.1458. Debo el dato de la fecha y la confirmación de la autoría de la rúbrica a Paula Pita Galán.

${ }^{40}$ Cfr. E. Zaragoza Pascual, "Abadologio del monasterio de San Martín Pinario (898-1835)", Compostellanum, 39, núms. 1-2 (en.-jun. 1994), pág. 229. Según otra referencia, el abad fray José Cornejo (1733-1737) hizo "el interior del dormitorio desde el [claustro] Norte hasta San Francisco" (ib., pág. 231).

${ }^{41}$ Cfr. A. Bonet Correa, La arquitectura en Galicia durante el siglo XVII, Madrid, 1984 (1 $1^{\mathrm{a}} \mathrm{ed}$. 1966), págs. 104-112; A. Vigo Trasancos, "La iglesia monástica de San Martín Pinario en Santiago de Compostela. Proyecto, fábrica y artífices”, Compostellanum, 38, núm. 3-4 (jul.-dic. 1993), págs. 337-361.

${ }^{42}$ Cfr. A. Bonet Correa, op. cit., 153-156; M. a D. Vila Jato, "Los grandes centros monacales", en J.M. García Iglesias, Santiago de Compostela, op. cit., págs. 288-289; A. Goy Diz, El arquitecto baezano Bartolomé Fernández Lechuga, Jaén, 1998, 80-84. A. Vigo Trasancos, "La iglesia monástica de San Martín...", art. cit., págs. 351-353, atribuye su traza a Ginés Martínez, aunque esto haya sido efectivamente construido por Fernández Lechuga, introduciendo algún cambio. Por contra, S. Vicente LóPez, Vega y Verdugo..., op. cit., págs. 55-59, se las otorga al fraile arquitecto Constantino Leitao de Vasconcellos, terminando siempre la obra el citado Fernández Lechuga.
} 
sido dibujado a mucha distancia, parece confundido con el cañón macizo de una torre, mientras el segundo, cuadrangular, abierto por un vano y coronado por un cupulín, es representado rematado con otra barra metálica ${ }^{43}$.

En el extremo derecho de las cubiertas del cenobio se yergue una estructura que se podría fácilmente confundir con un campanario cuando en realidad creo que corresponde a la silueta lateral de la peineta de la fachada de la portería, en la Plaza de la Inmaculada, obra de Fernando de Casas de 1738, no distinguiéndose, evidentemente, la escultura ecuestre de San Martín ${ }^{44}$.

No obstante, va ser la Plaza del Obradoiro, entonces el centro administrativo y político de la ciudad, en torno a la cual se distribuyan las sedes de los principales poderes de Compostela como eran el rey, el ayuntamiento, el arzobispo, el cabildo y la universidad. En la panda norte de la Plaza del Obradoiro se halla el Hospital Real, institución fundada por los Reyes Católicos, tras su visita de 1486. Sólo se representa la fachada oeste del edificio, diferenciándose en el grabado dos partes (contrastar figs. 3 y 5). La primera, hacia el Obradoiro, corresponde a los claustros renacentistas del famoso arquitecto Enrique Egas, y se distingue por sus hileras de ventanas y un tejado a mayor altura. En cambio, la segunda pertenece a los dos nuevos claustros barrocos traseros, construidos entre 1760 y 1768, según planos del arquitecto dominico fray Manuel de los Mártires, y se caracteriza por disponer de tres hileras de ventanas y la cubierta a menor elevación ${ }^{45}$. Tal desnivel hoy no es tal tras haberse añadido en los años cincuenta un nuevo piso a esa zona del edificio al reformarlo para convertirlo en Parador Nacional y Albergue de Peregrinos ${ }^{46}$. Afortunadamente, viejas fotografías y postales permiten confirmar las diferentes alturas representadas ${ }^{47}$ (contrastar figs. 3 y 9). No se ha dibujado el cimborrio de la capilla. La fachada se dispone paralela a la muralla, prácticamente desaparecida en este sector, salvando un gran desnivel y habilitando un gran patio de servicio o corral muy útil para la entrada de carros de leña, vituallas y otros productos con los que abastecer al centro. Tanto en nuestro grabado, como en la planimetría de la ciudad y en un plano

\footnotetext{
${ }^{43}$ Presenta la fecha grabada en la piedra, siendo su autoría controvertida; cfr. A. BonET CoRREA, op. cit., 447-449; J. M. García Iglesias, Santiago de Compostela, op. cit., pág. 295.

${ }^{44}$ Cfr. A. FernándeZ GonZÁLEZ, op. cit., págs. 209-217.

${ }^{45}$ Cfr. A.A. Rosende Valdés, El Grande y Real Hospital de Santiago de Compostela, Santiago, 1999, págs. 11-219.

${ }^{46}$ Cfr. A.B. Freire Naval, "La transformación del Hospital Real de Santiago en Parador de Turismo", en A. Bugallo Rodríguez y otros (comisarios), El Hospital Real de Santiago de Compostela y la Hospitalidad en el Camino de Peregrinación, catálogo de exposición, Santiago, 2004, págs. 529-546.

${ }^{47}$ Véanse ejemplos en Tarxetas postais: Santiago de Compostela. Colección Uxio de la Riva Pol, Museo do Pobo Galego, Gran Enciclopedia Gallega, 1981, pág. 131 (postal 96) y J.L. CABo ViLlaverde y P. Costa Buján, Compostela. Memoria fotográfica, Santiago, 1996, págs. 15.
} 


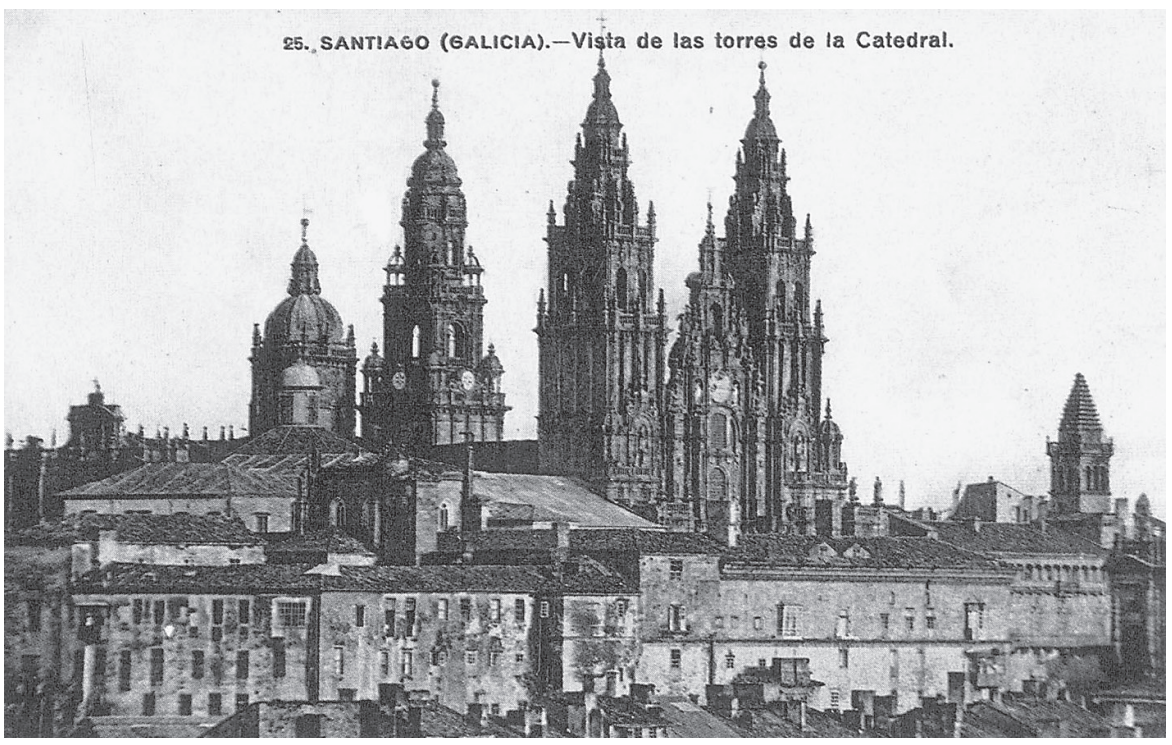

Fig. 9

Postal del Hospital Real y la Catedral (ca. 1910).

de Miguel Ferro Caaveiro de 1799, vemos cómo la cerca, salvo en la zona del torreón-mirador, ha sido sustituida por una manzana de casas, donde entonces vivía parte de su personal como el sangrador con su mujer, el organista y otros ${ }^{48}$ (figs. 3, 4 y 10). Curiosamente por la inclinación del terreno, estas viviendas contaban con una puerta hacia Carretas en la planta baja de su fachada principal y con otra en la planta superior, en la fachada posterior, hacia el corral del Hospital, permitiéndoles acceder cómoda y rápidamente a su lugar de trabajo. Más hacia el norte, en la desembocadura de la calle, detrás de las primeras casas, se hallaba la huerta, descrita en el plano de Ferro Caaveiro como terreno peñascoso muy inclinado.

En tiempos de López Freire la función principal del complejo consistía en dar asistencia sanitaria a la población de la ciudad y la comarca, también a la tropa del Cuartel de Santa Isabel, así como la acogida de expósitos, siendo muy secundaria su función de hospedería de peregrinos para la que fue fundado aunque todavía se les reservaban varias camas $^{49}$. Otro plano de 1799 con las dos

${ }^{48}$ Plano estudiado por A.A. Rosende Valdés, El Grande y Real Hospital..., op. cit., págs. 214216. Véase buena reproducción en A. Vigo Trasancos, J. Sánchez García y M. Taín Guzmán, op. cit., págs. 762 (dib.1.170).

${ }^{49}$ Cfr. B. Barreiro Mallón y O. Rey Castelao, Pobres, peregrinos y enfermos. La red asistencial gallega en el Antiguo Régimen, Santiago-Vigo, 1999, págs. 169-181. Según los estatutos de 
plantas del edificio, firmado también por Miguel Ferro Caaveiro, nos informa de los diversos usos de sus estancias, aunque aquí sólo vamos a analizar las de la panda occidental del grabado ${ }^{50}$. En la planta baja, de derecha a izquierda, la primera ventana corresponde al Alojamiento de Peregrinos y las siguientes a la Cocina de los capellanes; la Botica y los laboratorios; la Secretaria, el Archivo y la habitación del secretario; y el Archivo Nuevo ${ }^{51}$. En cambio, en la planta noble, la primera ventana pertenece a la Sala Real y el resto a Habitaciones del Administrador; la Enfermería de San Sebastián; los Cuartos de los Capellanes y Acólitos; y el Cuarto del Teniente Administrador. Como en los otros frentes de edificios de similar orientación, tan gran número de vanos permiten la entrada de luz y del aire cálido de la tarde. En el arranque del bloque posterior figura un esconce hacia el corral que albergaba las letrinas del centro, hoy desaparecido, pero cuya existencia documentamos en viejas fotografías (contrastar figs. 3 y 9).

La cara oeste de la plaza la cierra el Palacio de Rajoy, el inmueble de mayor impacto visual en la vista de López Freire. Entonces se acababa de terminar de construir siguiendo trazas de 1767 del ingeniero Charles Lemaur, lo que explica la ascendencia francesa del clasicismo de su arquitectura ${ }^{52}$. Su nombre denota que fue el arzobispo Bartolomé Rajoy y Losada quien financió su construcción en el solar de la antigua cárcel de la ciudad, dedicando el nuevo inmueble a Ayuntamiento, Cárcel Eclesiástica, Cárcel Seglar y Seminario de Confesores. Dada la zona desde donde se han tomado las notas del grabado, se representa la fachada trasera del inmueble, hacia la Rúa da Trinidade, con sus seis pisos de tragaluces y ventanales abiertos hacia el valle del Sarela y el sol de la tarde (contrastar figs.3 y 5). La necesidad de luz y ventilación, así como la multifuncionalidad del edifico, explican el amplio patio trasero, habilitado sobre las tres

Carlos V, se debía dar albergue a los peregrinos por un máximo de tres días en verano y cinco en invierno; cfr. Constituciones del Gran Hospital Real de Santiago de Galicia hechas por el Señor Emperador Carlos Quinto, Valladolid?, 159?, constitución núm. 50.

${ }^{50}$ Plano estudiado por A.A. Rosende VAldÉs, El Grande y Real Hospital..., op. cit., págs. 184-186 y 216-217. Del mismo hay una copia con fecha de 1800. Véanse buenas reproducciones de ambos en A. Vigo Trasancos, J. Sánchez García y M. Taín Guzmán, op. cit., pág. 871 (dibs. 1.403 y 1.404).

${ }^{51}$ Sobre la historia de esta última estancia véase A.A. Rosende ValdÉs, El Grande y Real Hospital..., op. cit., págs. 203-206.

${ }^{52} \mathrm{Su}$ construcción fue dirigida por el padre de López Freire, junto con Alberto Ricoy; cfr. Ma . del S. Ortega Romero, "Noticias sobre la construcción del Ayuntamiento de Santiago de Compostela", Cuadernos de Estudios Gallegos, 21, fasc. 63 (1966), págs. 81-101; F. Singul, op. cit., págs. 274299; A. A. Rosende VAldÉs, Una historia urbana ..., op. cit., págs. 294-309; J. Raposo Martínez, "Un cierto gusto por el arte francés en Santiago de Compostela: el Seminario de Confesores del arzobispo Bartolomé Rajoy y Losada (1690-1772)", en Actas del XVIII Congreso del CEHA: Mirando a Clío. El arte español espejo de su historia, Santiago de Compostela, 20-24 de septiembre de 2012, Santiago, 2012, págs. 1552-1564. 
primeras plantas y abierto también hacia el oeste, a modo de terraza, dando al inmueble forma de U. Igualmente el litigio con el Hospital Real por la proximidad de la nueva construcción, a la que van a acusar de privarles de sol y aire, dificultar la entrada de carros y hallarse muy próximo a su cementerio y capilla, de los que luego se tratarán, explica la peculiar disposición del esconce norte, perfectamente distinguible en la corografía ${ }^{53}$. Según Francisco Singul, los bajos del edificio hacia Trinidade se dedicaban a penitenciarías, las estancias en torno al patio de la U a Seminario y el esconce hacia el Hospital Real a Consistorio ${ }^{54}$. En el patio del inmueble sobresale en alzado una estructura ochavada, que destaca también en altura, y que pertenece a la capilla.

En la panda este se distinguen el Palacio Arzobispal, la Catedral y el Palacio Capitular aunque buena parte de los tres edificios quedan ocultos tras el volumen del palacio antes visto. En 1799 hacía unos meses que el Palacio Arzobispal había sido ocupado por el nuevo prelado Felipe Antonio Fernández Vallejo ${ }^{55}$. Como se sabe, su origen es una residencia medieval construida en el siglo XII por el arzobispo Diego Gelmírez, remodelado y/o ampliado en los siglos XIII, XIV, XVI, XVII y XVIII ${ }^{56}$. La representación en el grabado del frente hacia la Plaza del Obradoiro y la Rúa de San Francisco se corresponde a grandes rasgos con el actual, figurando el caserón del Obradoiro, adosado a la torre norte de la catedral, con la cual todavía hoy se halla comunicada desde el interior; el llamado Arco de Palacio, túnel medieval que comunica la citada plaza con la de la Azabachería; y la ampliación moderna por la Calle de San Francisco, un edificio debido al arzobispo Juan Beltrán de Guevara (1615-1622), como delata la presencia de su escudo en el inmueble (contrastar figs. 3 y 5). El primero, el más visible, presenta la fachada construida por el maestro de obras Benito González de Araújo en 1611, bajo patrocinio de Maximiliano de Austria ${ }^{57}$. En realidad, se trata de una pantalla edificada cinco metros por delante del edificio medieval, que queda completamente oculto detrás, alterando considerablemente la iluminación original de sus estancias interiores. Su construcción se debió a la necesidad de sostener la estructura del viejo palacio que entonces amenazaba ruina,

\footnotetext{
${ }_{53}$ Cfr. F. Singul, op. cit., págs. 276-286.

${ }^{54}$ Ibídem, págs. 291-297.

${ }^{55}$ En realidad, pasó la mayor parte de su corto mandato en el Palacio de Lestrove, cfr. A. LóPEz Ferreiro, op. cit., vol.IX, Santiago, 1911, págs. 93-112.

${ }^{56}$ Cfr. F. Singul y B. Domínguez Román, Palacio de Gelmírez, Santiago, 2001. Sobre el palacio gelmiriano véanse J. L. SenRA, "El Palacio Episcopal”, en F. Singul y J. Suárez Otero (comisarios), Santiago. La Esperanza, Santiago, 1999, págs. 73-77; M. NúÑEz RodríGuez, "A la búsqueda del palacio perdido", en C. Fernández Cortizo, D. González Lopo y E. Martínez Rodríguez (eds.), Universitas. Homenaje a Antonio Eiras Roel, t. II, Santiago, 2002, págs. 15-30.

${ }^{57}$ Cfr. P. Pérez Costanti, Diccionario de artistas que florecieron en Galicia durante los siglos XVI y XVII, Santiago, 1930, pág. 251; A. Bonet Correa, op. cit., págs. 136 y 141.
} 
aprovechándose la ocasión para dignificar el frente. Consta de cuatro pisos, los tres primeros de vanos y el último con una balconada con baranda de hierro que no se distingue en el grabado pero que conocemos bien gracias a una fotografía de Thurston Thompson de $1866^{58}$. Era usada por el prelado, su familia e invitados para asistir a los festejos de la plaza como las fiestas del Apóstol, estas últimas parece que ya recuperadas en 1799 tras la prohibición años antes de celebrar corridas de toros y quemar pólvora en los fuegos de artificio ${ }^{59}$. A la izquierda de la residencia sobresale hacia el Obradoiro una torre que en la vista no despunta en altura, cuando en la aguada de Baldi sí, constituyendo una afirmación visual del poder temporal del arzobispo (contrastar figs. 2 y 3). Parece que se trata de un añadido del siglo XVI ${ }^{60}$, concebido para transformar el inmueble en la característica casa-torre de la Compostela del quinientos ${ }^{61}$.

Anexa al Palacio Arzobispal se halla la Catedral, constituyendo la panorámica urbana de López Freire la primera imagen del éxito de la "catedral sobrepuesta" barroca sobre la basílica medieval ya terminada, una nueva arquitectura triunfal de exaltación jacobea ${ }^{62}$. En efecto, en ella aparece la primera representación de la nueva fachada del Obradoiro, construida entre 1738 y 1750 siguiendo trazas del Maestro Mayor catedralicio Fernando de Casas $^{63}$. La perspectiva frontal de la representación, que coincide exactamente con la vista desde la zona de Sarela de Abaixo, así como el edificio de Rajoy, sólo permiten representar la peineta del hastial central y una parte de la torres de la Carraca y de las Campanas, las dos primeras fruto de la intervención dieciochesca (contrastar figs. 3 y 5). De la primera sólo se distingue la silueta, destacando el camarín del remate, en el dibujo terminado en una barra metálica, no diferenciándose nada de su decoración e iconografía. De la Torre de la Carraca se dibuja con cierta fidelidad el torreón

\footnotetext{
${ }^{58}$ Véase buena reproducción en J.L. Cabo Villaverde y P. Costa Buján, Imaxe de Compostela. Unha cidade de pedra nas vellas fotografías, Santiago, 1991, 71 y L. Fontanella, Thurston Thompson e o proxecto fotográfico ibérico, A Coruña, 1996, pág. 22. La galería actual data del siglo XX; cfr. F. Singul y B. Domínguez Román, op. cit., págs. 46 y 69-70.

${ }^{59}$ Son muy pocos los datos que hay sobre las fiestas en esos años; cfr. M. TAÍ́n GuZMÁN, "Arquitecturas festivas catedralicias: los castillos y las fachadas de los fuegos del Apóstol Santiago", Semata, 22 (2010), págs. 495-518, especialmente 503-504.

${ }^{60}$ Según A. López Ferreiro, op. cit., vol. VIII, Santiago, 1906, págs. 272-274, la autoría de la torre correspondería al maestro cantero Alonso Franco, quien en 1575 firmó un contrato para su construcción, bajo el auspicio del arzobispo Francisco Blanco. Todavía en 1584 Gaspar de Arce (el viejo) firma un contrato para ampliarla (cfr. S. ViCENTE LóPEZ, "Gaspar de Arce, la muralla y la casa de doña Mencía de Andrade", Compostellanum, 54, núms. 3-4 (jul.-dic. 2009), págs. 388-389). ${ }^{61}$ Cfr. A.A. Rosende Valdés, "La imagen urbanística de Compostela en tiempos de Carlos V", en A. Eiras Roel (coord.), El Reino de Galicia en la época del emperador Carlos V, Santiago, 2000, págs. 653-654.

${ }^{62}$ Cfr. V. Tovar Martín, “Arquitectura”, en El arte del barroco, Madrid, 1990, págs. 118-124.

${ }^{63}$ Cfr. A. Vigo Trasancos, La fachada del Obradoiro de la catedral de Santiago (1738-1750), Santiago, 1996, 51-101; A. Fernandez GonZález, op. cit., págs. 82-106.
} 
medieval, tradicionalmente atribuido al Maestro Mateo, reconocible por estar recorrido de fajas verticales que aprovechan los pilares medievales. Encima se halla la estancia cuadrangular de la carraca, el instrumento que se hace sonar en Semana Santa, cuando callan las campanas, y que le da su nombre actual, aunque no se sabe desde cuando está instalada. Luego, en lugar de la flecha pétrea superior, López Freire se inventa dos cuerpos más decrecientes y un cupulín terminado en otra barra.

Esta torre reproduce literalmente la arquitectura de la opuesta, unas décadas más antigua, llamada Torre de las Campanas. También aquí se vuelve a reutilizar el fuste medieval recorrido por los mismos listeles. Sobre él, el Maestro catedralicio José de la Peña de Toro construyó entre 1663 y 1668 el cuarto de las campanas que le dan su nombre y que sirven para anunciar con sus tañidos las celebraciones de la Catedral $^{64}$. Como en el caso anterior, la aguja es sustituida por el remate inventado ya visto.

Detrás del hastial, parcialmente oculta y repitiendo su silueta, se halla la cúpula del crucero, obra del citado Peña de Toro, construida entre 1664 y $1666^{65}$ sobre un cimborrio octogonal gótico preexistente, no discernible en el grabado ${ }^{66}$. A la izquierda de la Torre de la Carraca, emergiendo de la techumbre del Palacio Arzobipal, se yergue el que creo perfil lateral de la peineta de la fachada de la Azabachería, como antes hemos visto para el caso de la de San Martín Pinario hacia la Plaza de la Inmaculada, construida en 1765 siguiendo trazas del arquitecto académico Ventura Rodríguez ${ }^{67}$. En ambos casos la identificación se confirma porque su ubicación se corresponde con la perspectiva desde Sarela de Abaixo.

A la derecha de la Torre de las Campanas se eleva la otra gran altura de la catedral, la Torre del Reloj, obra del Maestro catedralicio Domingo de Andrade de $1680^{68}$. También en este caso se aprovecha un torreón medieval, la Torre del Rey de Francia, del siglo XV, cuyas bandas verticales aparecen bien representadas ${ }^{69}$. Sobre él se dispone la fábrica barroca, primero un cuerpo cuadrangular, que en

\footnotetext{
${ }^{64}$ Cfr. S. Vicente López, Vega y Verdugo..., op. cit., págs. 472-487.

${ }^{65}$ Ibídem, págs. 466-472

${ }^{66}$ Cfr. R. YzQuierdo Perrín, "El gótico. Arquitectura y escultura”, en X.M. García Iglesias, (dir.), La Catedral de Santiago de Compostela, Patrimonio Histórico Gallego, Catedrales, Laracha, 1993, págs. 268-269. Sobre la fecha de construcción véase J. Vázquez Castro, "Castillos en el aire. El inicio del cimborrio gótico de la catedral compostelana", Quintana, 8 (2009), págs. 245-269.

${ }^{67}$ Cfr. A. Vigo Trasancos, La catedral de Santiago y la Ilustración. Proyecto clásico y memoria histórica (1757-1808), Madrid, 1999, págs. 66-82; F. Singul, op. cit., págs. 190-197.

${ }^{68}$ Cfr. M. Taín Guzmán, Domingo de Andrade, Maestro de Obras de la Catedral de Santiago (1639-1712), Sada-A Coruña, 1998, vol.1, págs. 112-119.

${ }^{69}$ Sobre el torreón medieval reaprovechado véase J. VÁzquez Castro, "La Berenguela y la Torre del Reloj de la Catedral de Santiago", Semata, 10 (1998), págs. 118-145.
} 
el grabado aparece falsamente con los muros dispuestos en talud. Su función es contener la campana de horas, razón por la que cada cara se abre hacia la ciudad. No figura el reloj, pese a su importancia como regulador de los horarios de la vida social, económica y municipal de Compostela, pero sí los templetes de las esquinas de función todavía no aclarada -¿pebeteros? ¿luminarias?- que creo relacionada con el uso del edificio en las fiestas. Le sigue el cuerpo octogonal de la campana de cuartos, abierto en cada lado por un vano, en el grabado mal dibujado, y sin los cuatro templetes de las esquinas. López Freire tampoco representa con la fidelidad debida el remate, la cúpula y la farola que a modo de faro jacobeo se enciende en los Años Santos señalando el camino a los peregrinos.

El enorme volumen del claustro renacentista catedralicio sólo se intuye gracias a la representación de los palacios y torres a él superpuestos. Me refiero al Palacio Capitular en la cara occidental, a la Torre de la Vela en el flanco sur y a la Torre del Tesoro en el este. El primero fue construido entre 1559 y 1599, siguiendo, al parecer, trazas de Rodrigo Gil de Hontañón ${ }^{70}$. Su nombre viene de albergar la Sala Capitular, en 1799 la actual del Maestro catedralicio Lucas Ferro Caaveiro, construida después del incendio del edificio de $1751^{71}$. En el grabado sólo se representa la galería alta, una columnata con zapatas sobre una volada repisa de sostén, utilizada por el cuerpo capitular para asistir a las citadas corridas de toros y los fuegos.

En el extremo suroccidental se eleva la Torre de la Vela, de cronología, autoría y finalidad controvertida, aunque claramente inspirada en su pareja la Torre del Tesoro y de la que sólo identificamos su último cuerpo y, sobre todo, su característico remate piramidal escalonado, posible evocación, como propone Rosende Valdés, de las representaciones imaginarias del Mausoleo de Halicarnaso, aludiendo al destino de la catedral como panteón apostólico y del vecino claustro como cementerio capitular ${ }^{72}$. Lo mismo se puede decir del remate de la Torre del Tesoro, el único elemento que se representa del Palacio del Tesoro en la Plaza de las Platerías, obra de Rodrigo Gil de Hontañón de entre 1543 y 1555, destinado en origen a guardar en su interior el archivo y los objetos más valiosos de la Catedral, el tesoro que le da su nombre, tanto los adquiridos por el cabildo para solemnizar la liturgia, como los regalados al Apóstol por reyes, nobles y peregrinos $^{73}$. Ambas torres aparecen en el dibujo con mástiles y banderas que

\footnotetext{
${ }^{70}$ Cfr. A.A. Rosende Valdés, "El siglo XVI: Gótico y Renacimiento en la catedral compostelana", en M. Núñez Rodríguez (ed.), Santiago, la catedral y la memoria del arte, Santiago 2000, págs. 148-150 y $154-157$.

${ }^{71}$ Cfr. E. Beiras García, Lucas Ferro Caaveiro e a cidade de Santiago de Compostela, Fundación Caixa Galicia, 2008, págs. 27-63.

72 Cfr. A.A. Rosende Valdés, "El siglo XVI...", op. cit., págs. 152 y 156.

${ }^{73}$ Ibídem, págs. 147-148 y 150-154; sobre la torre págs. 152-153.
} 
sabemos estaban "pintadas" y se colocaban en julio con motivo de las fiestas del Apóstol ${ }^{74}$, constituyendo este grabado el único testimonio visual de una costumbre bien documentada, un detalle que podría indicar el momento del año de la realización del dibujo.

Cerrando el sur del Obradoiro se representa el Colegio de San Jerónimo, levantado entre 1650 y 1658, en la antigua huerta del vecino Colegio de Fonseca. El edificio lo construyeron los arquitectos Diego Ibáñez Pacheco, primero, y Jácome Fernández (hijo), después, siguiendo trazas de Ibáñez que se inspiran en unas anteriores de Fernández Lechuga, mientras que el claustro corresponde a Peña de Toro $^{75}$. López Freire sólo dibuja la fachada oeste, caleada, funcional y con ventanas hacia el jardín (contrastar figs. 3 y 5). En 1799 San Jerónimo todavía funcionaba como colegio menor de estudiantes de Artes, con crecientes dificultades por la reciente instalación de la sede de la universidad en el antiguo colegio de los Jesuitas ${ }^{76}$.

El Colegio de Santiago Alfeo, más conocido como Colegio de Fonseca, construido entre 1532 y 1544, con trazas de Juan de Álava y Alonso de Covarrubias, aparece representado a continuación, a menor altura, dando su fachada oeste también al jardín ${ }^{77}$ (contrastar figs. 3 y 5). Según dos planos del siglo XVIII la hilera de ventanas de la planta baja corresponde a las cátedras del centro y la del primer piso a cuartos de los colegiales ${ }^{78}$. La torre que asoma por encima de los tejados de San Jerónimo es, en realidad, la Torre del Reloj de este colegio, aunque en el grabado se le da una altura exagerada y una forma extraña. Se halla en el ángulo nororiental del inmueble, adosada a la fachada principal, data de 1601 y se construyó siguiendo trazas del arquitecto Mateo López ${ }^{79}$. En el grabado se distingue el fuste de la torre y el cuerpo superior. El reloj, que da nombre al edificio y no se representa, con la ayuda de dos campanas en un chapitel de hierro que tampoco figura en el grabado, servía para regular la vida académica del

\footnotetext{
${ }^{74}$ Cfr. M. TAín Guzmán, “Arquitecturas festivas catedralicias...”, art. cit., pág. 503.

75 Cfr. A. Bonet Correa, op. cit., págs. 305-307; A. Goy Diz, El arquitecto baezano..., op. cit., págs. 115-123; A.A. Rosende VAldÉs, Una historia urbana..., op. cit., págs. 289-294; L. FERNÁNDEZ Gasalla, "El arquitecto José de la Peña de Toro (1614-1676)", Compostellanum, 51, núms. 3-4 (2006), págs. 349-350; S. Vicente LóPeZ, Vega y Verdugo..., op. cit., págs. 72-84.

${ }^{76}$ Cfr. X.R. BArreiro (coord.), Historia da Universidade de Santiago de Compostela, vol. I, Das orixes ó século XIX, Santiago, 1998, págs. 265-267.

77 Cfr. A. Fraguas Fraguas, O Colexio de Fonseca, Santiago, 1995 (reed. conjunta de Historia del Colegio de Fonseca, Madrid, 1956 y Los colegiales de Fonseca, Cuadernos de Estudios Gallegos, 1958), págs. 15-194; A. Castro Santamaría, Juan de Álava, arquitecto del renacimiento, Salamanca, 2002, págs. 457-470.

78 Véanse buenas reproducciones en A. Vigo Trasancos, J. Sánchez García y M. Taín Guzmán, op. cit., págs. 844-845 (dibs. 1354 y 1355).

${ }^{79}$ Cfr. A. Fraguas Fraguas, op. cit., págs. 144-149.
} 
centro y evitar las faltas a las clases ${ }^{80}$. En 1799 residían en el inmueble alrededor de doce colegiales ${ }^{81}$, funcionando todavía como colegio de grados mayores en Artes, Cánones, Leyes y Teología ${ }^{82}$.

Del Monasterio de San Pelayo sólo se representan parcialmente algunos detalles ya que en gran medida queda oculto detrás de los inmuebles que tiene delante, coincidiendo lo representado con la vista desde la aldea de Sarela de Abaixo (contrastar figs. 3 y 5). Así, asomando detrás de la Torre de la Carraca, a la izquierda, se halla la iglesia, con el cimborrio de su cúpula, su tejado y su linterna, en el grabado de altura exagerada, construida entre 1699 y 1707 por Fray Pedro de San Bernardo, Fray Gabriel de las Casas y Pedro García, en diferentes momentos, siguiendo trazas de autoría no aclarada ${ }^{83}$. En cambio, detrás de la Torre del Reloj, a ambos lados, se encuentra el edificio de celdas de las monjas benedictinas, en la plaza de la Quintana, obra de Jácome Fernández (hijo), construido entre 1641 y 1658, siguiendo trazas de Fernández Lechuga ${ }^{84}$. En el grabado sólo se representa la hilera de ventanas del último piso. En 1786 vivían en él parte de las alrededor de cincuenta monjas del monasterio, originarias de las más ilustres familias de la nobleza gallega, aparte de novicias, educandas y $\operatorname{criadas}^{85}$.

Desde Sarela de Abaixo, el monte de Santa Susana, sus robles y arboledas nos impiden apreciar las casas y monumentos sitos en la zona del sur de la ciudad, de la que sólo se aprecia parte de la Universidad. Por lo tanto, la representación de este edificio en el grabado, junto con algunos tejados del caserío y las elevaciones de tres iglesias, solo se explicaría por el cambio de ubicación del artista a una altura muy próxima al punto anterior para la toma de notas. En consecuencia, como ya he expuesto, sospecho que para mostrar esta zona, o más bien sugerirla, el artista ascendió al Pereiros, desde donde podría terminar de dibujar el citado inmueble, seguido del campanario de la antigua iglesia de los Jesuitas, hoy de dicha Universidad, y, acaso, la Casa de Ejercitantes, actualmente Facultad de Filosofía, cuya presencia aclararía la forma del centro (contrastar figs. 3 y 6). Si estuviera en lo cierto, tal atribución justificaría que del primero

\footnotetext{
${ }^{80}$ Cfr. P. Pérez Costanti, "La Torre y el reloj del Colegio de Fonseca", Notas Viejas Galicianas, t. III, Vigo, 1926, págs. 323-328.

${ }^{81}$ Cfr. X.R. BARreiro, Historia da Universidade..., op. cit., vol. I, pág. 257.

${ }^{82}$ Ibídem, págs. 255-261.

${ }^{83}$ Cfr. L. Fernández Gasalla, La arquitectura en tiempos de Domingo de Andrade, Universidad de Santiago, 2004, t. II, págs. 1177-1190.

${ }^{84}$ Cfr. A. Goy Diz, El arquitecto baezano..., op. cit., 159-169; A.A. Rosende VAldÉs, Una historia urbana..., op. cit., 193-196; A. Goy Diz, "El resurgir de los monasterios en el Renacimiento", en J.M.B. LóPez VÁzQuez, Opus monasticorum. Patrimonio, arte, historia y orden, Galicia, 2005, págs. $160-162$

${ }^{85}$ Cfr. M.B. García M. Colombás, Las señoras de San Payo. Historia de las monjas benedictinas de San Pelayo de Antealtares, Madrid, 1980, págs. 313-320.
} 
se representasen sólo las pandas este y norte del claustro, la primera de aulas y la segunda con aulas y la biblioteca en la planta superior, pues la oeste estaba todavía en construcción ${ }^{86}$. También la presencia del campanario-espadaña de la iglesia, entonces ya de la Universidad aunque compartida con la Cofradía del Santo Espíritu ${ }^{87}$, construido en 1719, como consta en una inscripción del entablamento $^{88}$. López Freire lo dibuja frontal y fielmente, lo que la hace parecer una gran torre cúbica, efecto perspectivo buscado por su autor y que pierde de perfil por su delgadez ${ }^{89}$. Como en el grabado, el edificio, de planta rectangular, cuenta con un primer cuerpo con dos arcos y el segundo decreciente con uno solo y se termina en un cupulín. Le sigue a continuación el Caserón de Ejercitantes, inmueble superviviente del antiguo Colegio de los jesuitas, construido con trazas del arquitecto Simón Rodríguez, en la década de 1730, como casa de ejercicios del clero diocesano y sede de una escuela de gramática ${ }^{90}$.

En cuanto a las iglesias de la vista, desde el montículo citado se observan, después de la Universidad y hasta la parroquial de Santa Susana, en la cima del otero al que da nombre, de izquierda a derecha, el campanario de la parroquial de Salomé, de $1743^{91}$, el campanario de la iglesia del Colegio de las Huérfanas, de $1714^{92}$, la linterna de la cúpula de dicha iglesia, de $1664^{93}$, y, por fin, la linterna de la cúpula de la iglesia de las Mercedarias, de 1674, convento sito ya fuera de la muralla ${ }^{94}$. Imposible dilucidar cuál es cual en el grabado por la simplicidad de lo dibujado, si bien es verdad que, como figura en la corografía, sólo los tres últimos emergen aún hoy por encima de la arboleda (fig. 6).

Entre el caserío compostelano todavía quedan por identificar algunas estructuras de cierto empaque: por ejemplo el elevado volumen situado a la izquierda de la peineta catedralicia de la Azabachería, tal vez referencia visual a la recién terminada iglesia parroquial de San Benito ${ }^{95}$ (fig. 3). También llaman la aten-

\footnotetext{
${ }^{86}$ Cfr, F. Singul, op. cit., págs. 126-130.

${ }^{87}$ Cfr. E. Rivera Vézquez, Galicia y los Jesuitas. Sus colegios y enseñanza en los siglos XVI y XVIII, La Coruña, 1989, pág. 653.

${ }^{88}$ Cfr. Ma. del C. Folgar de la Calle, "Los conventos", en X.M. García Iglesias, Santiago de Compostela, op. cit., pág. 403.

${ }^{89}$ Cfr. A. Bonet Correa, op. cit., pág. 468.

${ }^{90}$ Cfr. E. Rivera VázQuez, op. cit., pág. 224-225.

${ }^{91}$ Cfr. R. Yzquierdo Perrín, "Santa María Salomé", en X.M. García Iglesias, Santiago de Compostela, op. cit., pág. 188-189.

${ }^{2}$ Cfr. A. Fernández González, op. cit., pág. 262

${ }^{93}$ Cfr. P. Pérez Costanti, Diccionario..., op. cit., pág. 552; A. Bonet Correa, op. cit., pág. 320321.

${ }^{94}$ Cfr. Ma . del C. Folgar de la Calle, "Los conventos", en X.M. García Iglesias, Santiago de Compostela, op. cit., págs. 392-393.

${ }^{95}$ Cfr. F. Singul, op. cit., págs. 349-357. Se aludiría a su remate con un frontispicio triangular, sin el actual campanario.
} 
ción algunas ausencias, particularmente la iglesia de San Agustín, aunque en este caso el motivo podría deberse a que un rayo habría destruido la torre del evangelio la noche del 28 de febrero de $1788^{96}$, mientras que su pareja quedaría parcialmente oculta entre la Torre de las Campanas y la Torre del Reloj de la Catedral vista desde Sarela de Abaixo, cancelándose su representación para evitar confusión ${ }^{97}$ (fig. 3). El Colegio de San Clemente tampoco figuraría por hallarse escondido detrás de Santa Susana.

Como las vistas de 1666 y 1669, la de López Freire también testimonia como la muralla no ha podido contener el crecimiento demográfico de la ciudad, expandiéndose en barrios extramuros, muchos de ellos de origen medieval, vinculados a las puertas, todavía en pie en $1799^{98}$, y a los caminos que salen de ellas, así como a los conventos situados en el extrarradio ${ }^{99}$. Al norte representa los barrios de Santa Clara y San Francisco, uno desarrollado al borde del camino real que conduce a A Coruña y el otro del camino que conduce a Santa Comba. En el primero figura el Convento de San Clara, que le da su nombre, dibujándose el enorme bloque de celdas que linda con el camino, "durmitorio" se le llama en la documentación, con sus dos hileras de vanos, construido entre 1719 y la década de 1740 por varios arquitectos, según Folgar de la Calle siguiendo trazas de Simón Rodríguez ${ }^{100}$ (contrastar figs. 3 y 5). A la derecha, frontalmente, figura la fachada de la portería y, apenas esbozado, su artístico remate con cilindros de piedra, una de las obras maestras de la arquitectura barroca compostelana, de 1721 y debida al mismo arquitecto ${ }^{101}$. Sobre las techumbres se eleva el campanario de la iglesia, que todavía subsiste, de cronología no aclarada, constando de un único cuerpo para las campanas y la media naranja habitual. Su presencia se relaciona con la ubicación de la iglesia en esa zona, oculta tras el edificio dibujado $^{102}$.

A un nivel inferior, aprovechando la pendiente del terreno, aparece el Convento del Carmen, entonces uno de los más modernos de Compostela, fundado en 1748 por la Madre María Antonio de Jesús ${ }^{103}$. El complejo conventual se construyó entre 1753 y 1792, al parecer siguiendo trazas del fraile arquitecto

\footnotetext{
${ }^{96}$ Cfr. Ma . del C. Folgar de la Calle, "Los conventos", en X.M. García Iglesias, Santiago de Compostela, op. cit., pág. 413.

${ }^{97}$ Desde el Pereiros la iglesia queda completamente oculta detrás de las torres de la catedral.

${ }^{98}$ Cfr. A.A Rosende Valdés, Una historia urbana ..., op. cit., págs. 55-84.

${ }^{99}$ Cfr. J.A. Armas Castro, op. cit., págs. 94-96.

${ }^{100}$ Cfr. Ma . del C. Folgar de la Calle, Simón Rodríguez, La Coruña, 1989, págs. 56 y 66.

${ }^{101}$ Ibídem, págs. 55-64.

${ }^{102} \mathrm{Cfr}$. M ${ }^{\mathrm{a}}$. del C. Folgar de la Calle, "Los conventos", en X.M. García Iglesias, Santiago de Compostela, op. cit., págs. 343-345.

${ }^{103}$ Cfr. Una mística gallega en el siglo XVIII. La Venerable Madre María Antonio de Jesús. Fundadora del Convento de Carmelitas Descalzas de Compostela, A Coruña, 1991.
} 
Fray José de los Santos, constituyendo este grabado su primer testimonio gráfi$\mathrm{co}^{104}$. En él figura el bloque de celdas de las monjas, con dos hileras de ventanas orientadas hacia la huerta y al sol de la tarde (contrastar figs. 3 y 5). Sobre los tejados asoma el volumen de la iglesia y, más a la derecha, el típico campanario, este último probablemente un error pues el inmueble cuenta con una espadaña.

Con mucho mayor detalle se representa la iglesia y edificios del Convento de San Francisco, particularmente la primera, recién terminada, construida entre 1742 y 1787 con trazas de Simón Rodríguez y la maestría de varios frailes $\operatorname{arquitectos}^{105}$ (contrastar figs. 3 y 5). En ella se reconoce con claridad su planta de cruz latina inscrita en un rectángulo. Cuenta con tres naves, las laterales más bajas, la central con contrafuertes para sostener las bóvedas interiores y con la pared horadada por ventanas para permitir la entrada de luz. La cabecera es muy profunda, y dispone de una enorme sacristía, dispuesta justo detrás, de menor elevación. El transepto, de gran tamaño, presenta un amplio vano en el testero oeste. Un cimborrio ochavado delata la existencia de una cúpula sobre el crucero. Dos torres flanquean la fachada representadas pegadas la una a la otra de una manera un tanto burda. Ambas presentan dos cuerpos decrecientes para las campanas, remate cupulado y aguja metálica. Su elevada altura se justifica por la aspiración de competir con el tañido de las campanas de otras iglesias de la ciudad y para dejar constancia de la presencia de la orden dentro y fuera de la muralla. Paralelos al templo, en su flanco occidental, se disponen los edificios de los dos claustros con fachada hacia la huerta. El sur, conocido como claustro de la portería, fue financiado por el arzobispo Maximiliano de Austria hacia 1611, atribuyéndose sus trazas al arquitecto Jácome Fernández (padre), mientras que el norte data de las décadas de 1630 y 1640 y se le relaciona con Juan González Araújo $^{106}$. Ambos abren sus ventanas hacia la huerta, en el grabado arbolada y cerrada. En 1799 el convento cuenta con un elevado número de frailes, siendo el padre guardián Miguel Fernández Sarela ${ }^{107}$. Sobresaliendo del complejo conventual y avanzando hacia la Costa de San Francisco, figuran unos edificios, con tres volúmenes. Los dos primeros corresponderían a la nave y al ábside cupulado, éste de mayor altura, de la Capilla de la Orden Tercera, edificio atribuible al arquitecto Domingo de Andrade y datable de entre 1676 y $1706^{108}$. En cambio,

\footnotetext{
${ }^{104}$ Cfr. Ma . del C. Folgar de la Calle, "Los conventos", en X.M. García Iglesias, Santiago de Compostela, op. cit., págs. 416-418.

${ }^{105}$ Ibídem, págs. 318-330.

${ }^{106}$ Ibídem, págs. 322-323.

${ }^{107}$ Cfr. M. Pazos, El convento de San Francisco de Santiago y sus dos iglesias, la actual y la derruida en 1741 (1518-1862), Liceo Franciscano, Santiago, 1979, págs. 248-249.

${ }^{108}$ Cfr. M. TAín Guzmán, Domingo de Andrade..., op. cit., vol.1, págs. 249-257.
} 


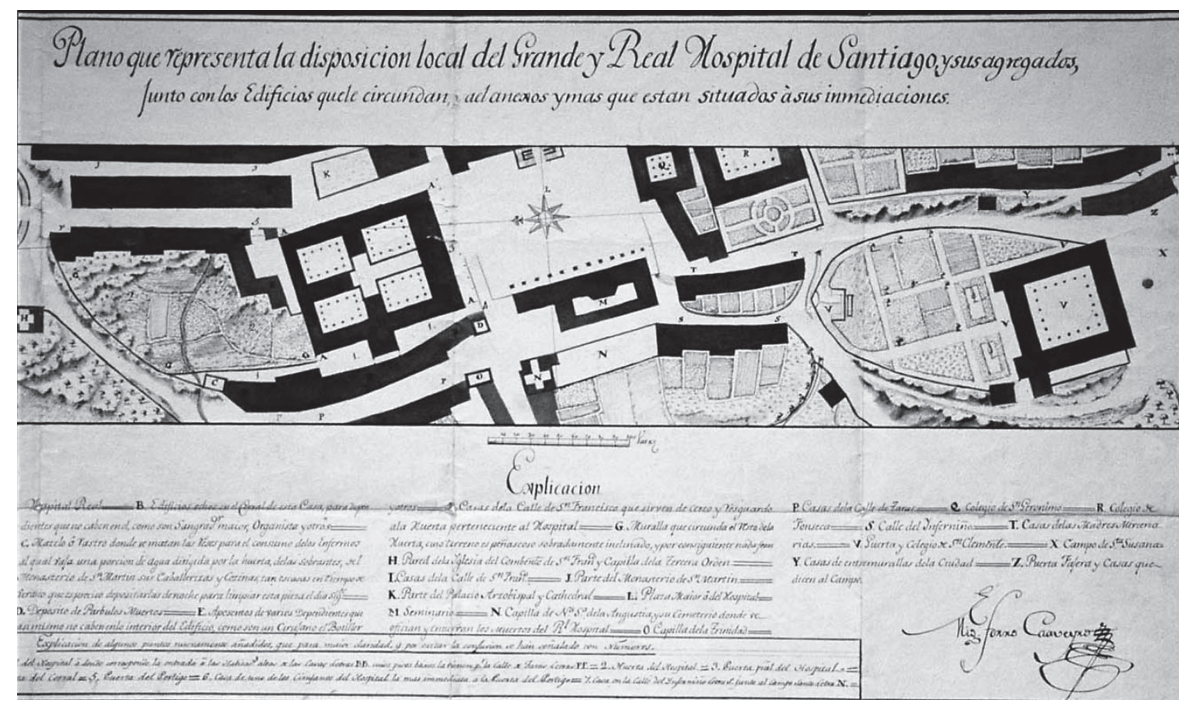

Fig. 10

Miguel Ferro Caaveiro: plano de la zona del Hospital Real y de la frente occidental de Compostela en 1799 (Archivo Histórico Nacional).

el tercero pertenecería a la sacristía, dispuesta justo detrás, obra de Fernando de Casas de entre 1716 y $1719^{109}$. El campanario no se representa.

Al oeste se distribuyen los barrios de Hortas-Pombal y Poza de Bar-San Lourenzo. En el primero distinguimos, en la embocadura de la calle, la Iglesia de la Trinidad, edificio hoy desaparecido del que apenas se sabe nada pero que ubicamos en las planimetrías de la ciudad (contrastar figs. 3, 4 y 10) y cuyo aspecto conocemos por alguna vieja fotografía ${ }^{110}$ (contrastar figs. 3 y 11). Éstas confirman la existencia del campanario representado. Su fundación es antigua pues ya se cita en el Códice Calixtino, donde se indica que constituía entonces el lugar donde se enterraban los peregrinos fallecidos en Compostela ${ }^{111}$. Según Sánchez Rivera, fue reedificada a principios del siglo XVII ${ }^{112}$. En 1799 se utilizaba como depósito de cadáveres de adultos ${ }^{113}$.

\footnotetext{
${ }^{109}$ Cfr. A. Fernandez GonZález, op. cit., págs. 267-269.

${ }^{110}$ Véase ejemplo en J.L. Cabo Villaverde y P. Costa Buján, Imaxe de Compostela..., op. cit., pág. 142. La iglesia fue demolida hacia 1934; cfr. C. SÁnchez Rivera, Notas Compostelanas. Historias, Tradiciones, Leyendas, Miscelánea, Santiago, s.a., pág. 86.

${ }^{111}$ Cfr. Liber Sancti Jacobi "Codex Calixtinus", traducción de A. Moralejo, C. Torres y J. Feo, Santiago, 1951, pág. 552.

${ }^{112}$ Cfr. C. SÁnchez Rivera, op. cit., pág. 85.

${ }^{113}$ Cfr. A.A. Rosende valdés, El Grande y Real Hospital..., op. cit., pág. 216.
} 


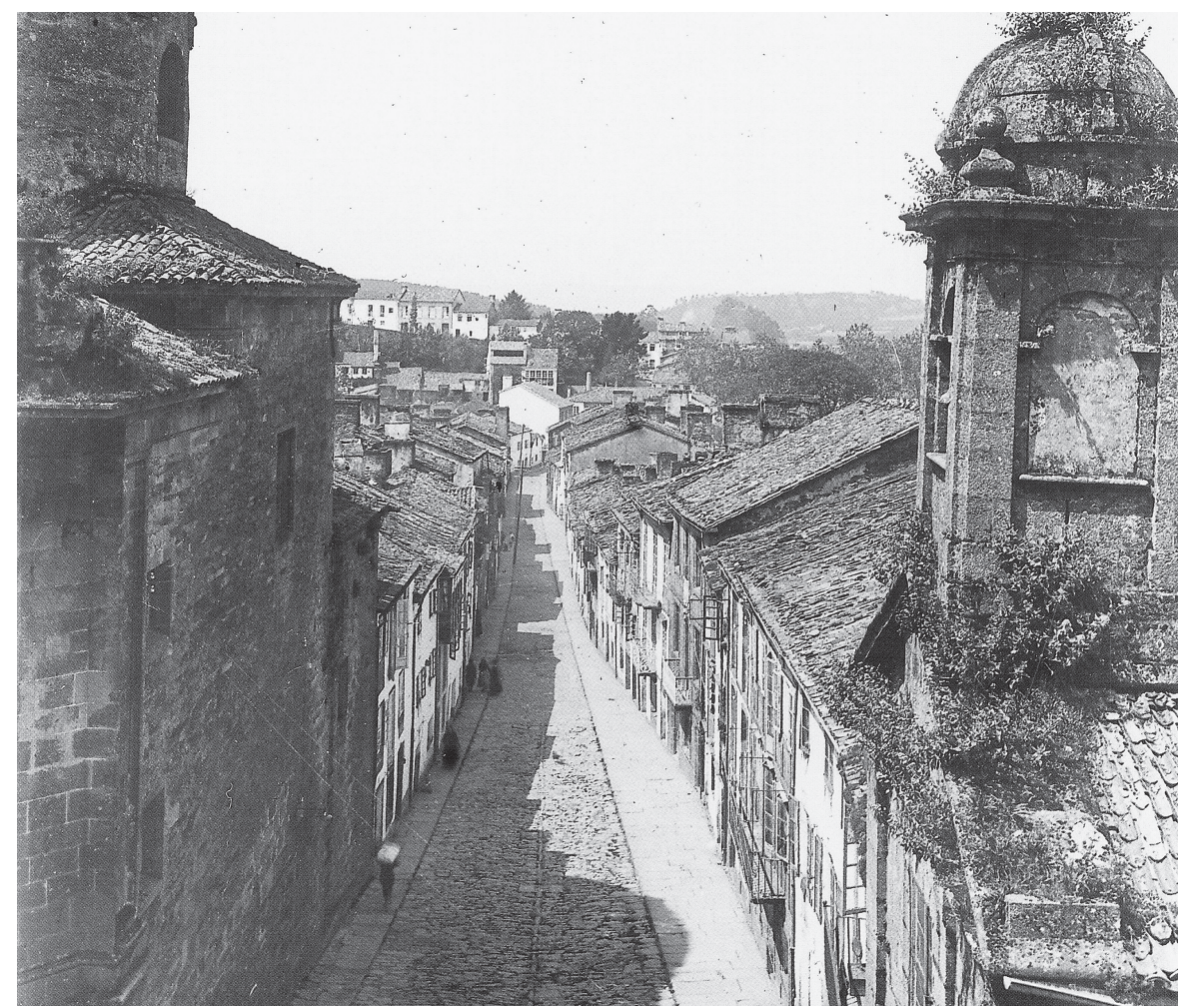

Fig. 11

Iglesia de la Trinidad, iglesia de San Fructuoso y Rúa das Hortas (c.1920).

Al otro lado de la calle, aunque con entrada por la Rúa da Trinidade, aparece la Capilla de Nuestra Señora de las Angustias de Abajo ${ }^{114}$, hoy iglesia parroquial de San Fructuoso ${ }^{115}$, construida entre 1754 y 1756, en que fue inaugurada, sustituyendo a una más antigua, en el cementerio de enfermos y peregrinos del Hospital Real, adquirido para tal función en 1508 y en uso hasta $1811^{116}$ (contrastar figs. 3 y 5). La financiación se obtuvo de las limosnas de los compostelanos por la devoción popular a una antigua imagen mariana de la Virgen de la Piedad ${ }^{117}$, encargándose de la traza a Lucas Ferro Caaveiro ${ }^{118}$. Templo de planta de cruz

\footnotetext{
${ }^{114}$ Llamada popularmente así para diferenciarla de una capilla de igual advocación en la Rúa da Angustia en el Barrio de San Pedro.

${ }^{115}$ Fue entregada a esta parroquia en 1920.

${ }^{116}$ Cfr. C. Sánchez Rivera, op. cit., págs. 85 y 115.

${ }^{117}$ Véase foto de la imagen en ibídem, págs. 117.

${ }^{118}$ Ibídem, págs. 115-130.
} 


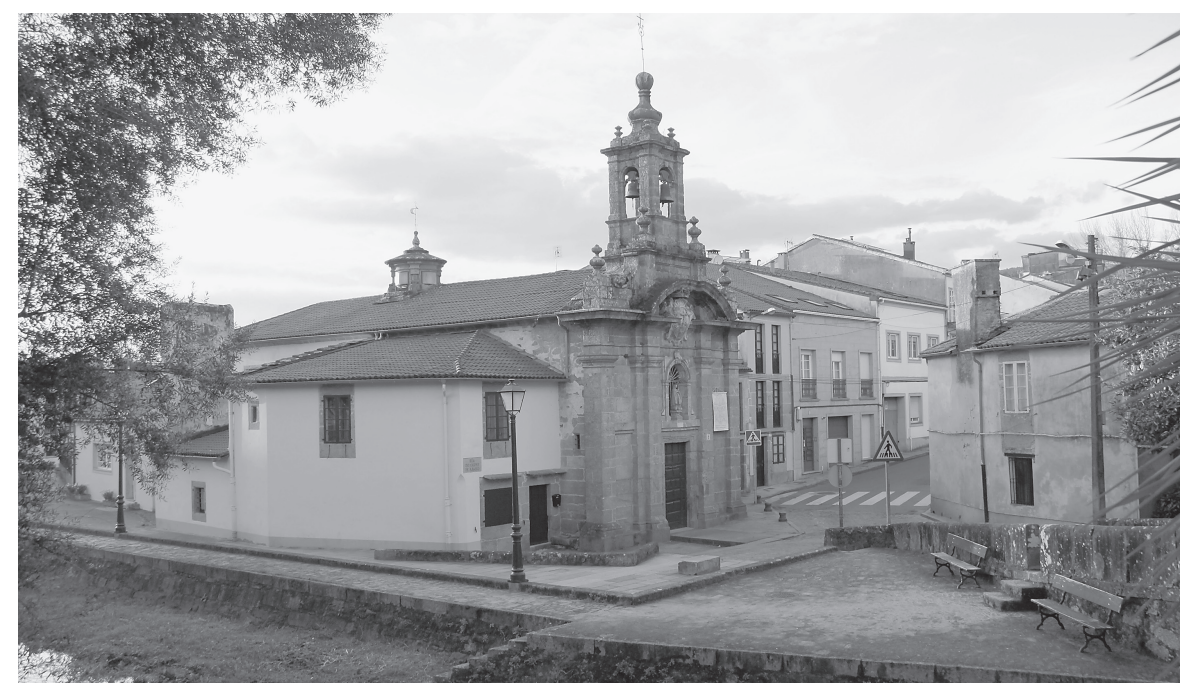

Fig. 12

Iglesia del Carmen de Abaixo.

griega, en el grabado se representan los brazos norte y oeste, así como el gigantesco cimborrio de la cúpula central.

Más abajo, a las orillas del Sarela, se reconoce la nave y el campanario de la Iglesia de Carmen de Abaixo, faltando, por el ángulo de la vista, el puente vecino (contrastar figs. 3 y 12). El edificio fue construido entre 1760 y 1773 por la cofradía de Nuestra Señora del Carmen fundada unos años antes, en 1749, por Juan Antonio Barreiro por su devoción a la Virgen de Carmen ${ }^{119}$. La imagen del grabado es anterior a la reforma de 1867 en que se procedió a alargar el edificio, construyendo un nuevo presbiterio, dejando el antiguo a modo de crucero ${ }^{120}$.

Siguiendo el valle del Sarela, en medio de una frondosa robleda, emerge el Convento de San Lorenzo de Trasouto, convento franciscano desde el siglo XIV, aunque de fundación más antigua, radicalmente remodelado en el siglo XVIII ${ }^{121}$. En el dibujo se representa el bloque occidental de celdas del recinto claustral, con sus dos hileras de ventanas, al parecer rehecho en tiempos del arzobispo

\footnotetext{
${ }^{119}$ Información facilitada por Domingo González Lopo.

${ }^{120}$ Cfr. J.M. López VÁzquez, "Nuestra Señora del Carmen de Abajo", en X.M. García Iglesias, Santiago de Compostela, op. cit., págs. 240-241.

${ }^{121}$ Cfr. Ma . del C. Folgar de la CAlle, "Los conventos", en X.M. García Iglesias, Santiago de Compostela, op. cit., págs. 350-352.
} 


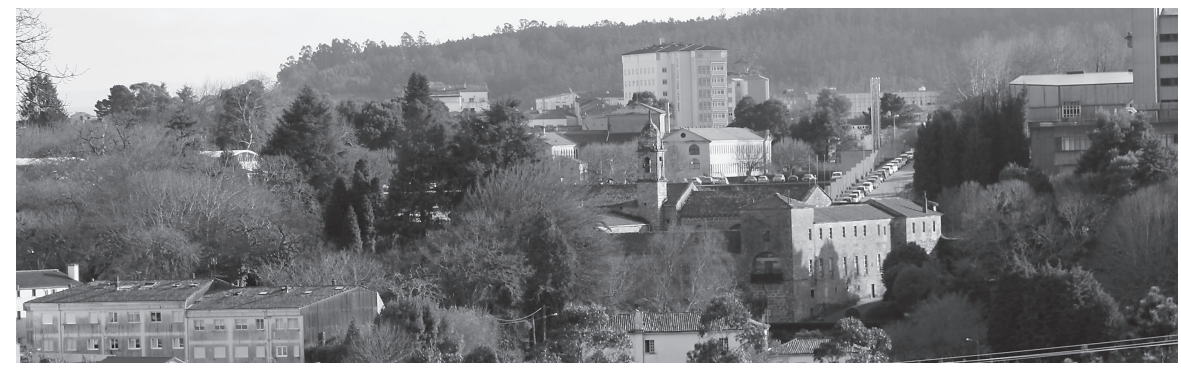

Fig. 13

Carballeira y Convento de San Lourenzo de Trasouto.

Fray Antonio de Monroy ${ }^{122}$ (contrastar figs. 3 y 13). También figuran varios edificios anexos. Un amplio muro cierra el bosque que llega al río, donativo de los Condes de Altamira a los frailes en el siglo XV, siendo desde entonces, y todavía en 1799 , patronos del convento ${ }^{123}$. Fuera del muro, entre las casas y el complejo, aún hay otra arboleda, la actual Carballeira de San Lorenzo, regalada por la misma familia a la ciudad en 1546 para uso y esparcimiento del vecindario y con la condición de que se planten árboles y "que no puedan cerrarlo ni aforarlo ni arrendarlo ni otra cosa alguna, syno questé abierto para pasto común e folgança, salido e serbidumbre de la ciudad, vecinos e moradores della"124. Así se le representa todavía en el grabado: muy poblado de robles y sin muros para disfrute de los compostelanos (contrastar figs. 3 y 13).

Detrás se sitúa el Monte de Santa Susana con su antigua carballeira, espacio público desde tiempo inmemorial, utilizado en 1799 por el vecindario como espacio de ocio y paseo $^{125}$. Lo interesante de la imagen de López Freire es que nos muestra el aspecto del otero y su arboleda unos años antes a su urbanización con la construcción de la Alameda y el Paseo de la Herradura ${ }^{126}$ (contrastar figs. 3 y 6). En su cúspide figura una iglesia que cabe identificar con la Iglesia parroquial de Santa Susana que le da su nombre, templo de origen medieval de una sola

\footnotetext{
${ }^{122} \mathrm{Cfr}$. M ${ }^{\mathrm{a}}$.T. Ríos Miramontes, Aportaciones al barroco compostelano. Un gran mecenazgo, Santiago, 1986, págs. 310-311.

${ }^{123}$ Cfr. P.A. LóPEz, "El convento de San Lorenzo de Trasouto, extramuros de la ciudad de Santiago de Compostela", Archivo Iberoamericano, 1933, págs. 396-397.

${ }^{124}$ Ibídem, págs. 396-398.

${ }^{125}$ Antonio Rioboo y Seijas escribe en 1753 que la ciudad cuenta con "un ameno paseo a la iglesia y campo de Santa Susana, poblado de robles en dos filas a cordel y asientos de cantería en que pueden acomodarse más de cien personas"; cfr. P. Pérez Costanti, Notas Viejas Galicianas, vol. I, Vigo, 1925, pág. 63.

${ }^{126}$ Cfr. F. Singul, op. cit., págs. 139-141.
} 


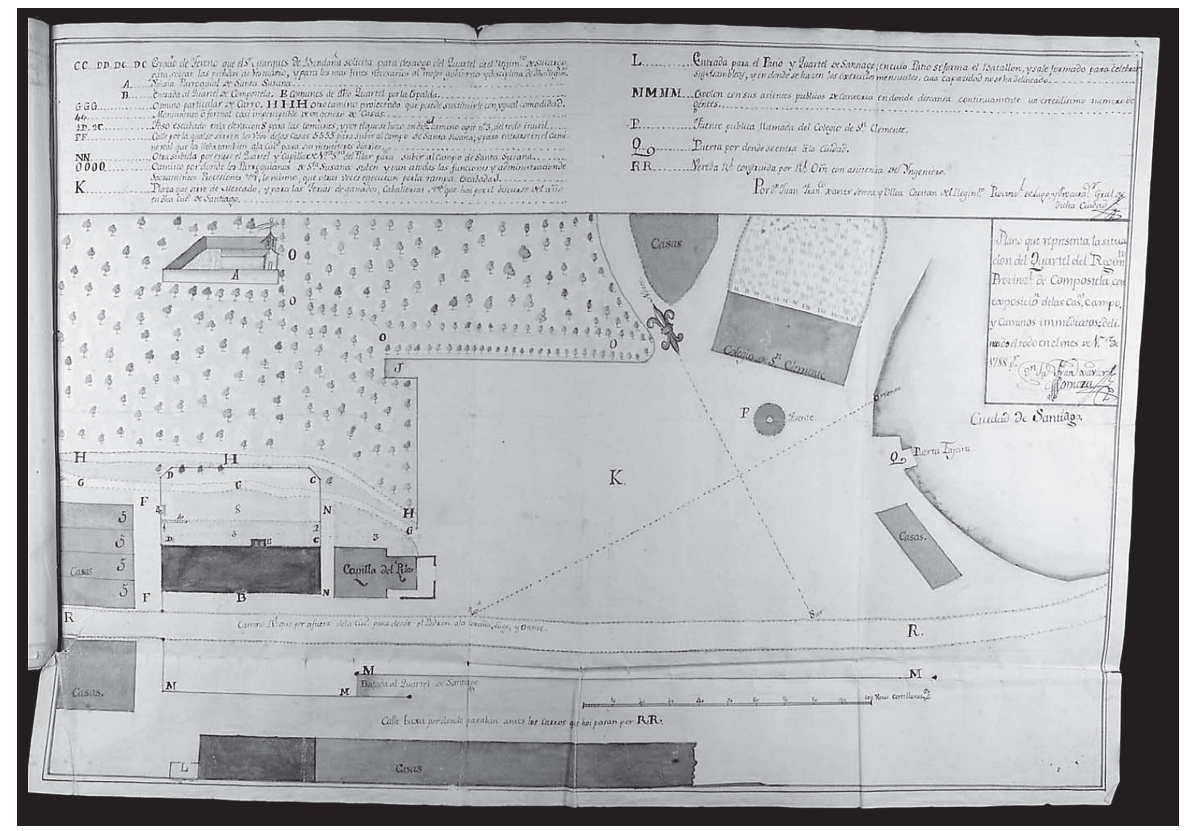

Fig. 14

Somoza y Ulloa: Campo de Santa Susana, 1788 (Archivo Histórico Universitario de Santiago).

nave, muy reformado después de la elaboración del grabado ${ }^{127}$ (contrastar figs. 3 y 6). Aquí aparece representada con un campanario que no es el actual sino el demolido en el siglo XIX mencionado por Murguía ${ }^{128}$. Un dibujo de la iglesia y su entorno de 1788 atestigua su existencia ${ }^{129}$ (fig. 14).

En la pendiente sur de la colina se encuentra una iglesia de doble campanario que corresponde a la Iglesia de Nuestra Señora del Pilar, edificio construido a principios del siglo XVIII, fundado por el canónigo catedralicio Juan Sánchez Vaamonde, arcediano de Nendos, y consagrado en $1717^{130}$ (contrastar figs. 3 y 15). Detrás del templo se distribuye el caserío en hileras a la vera del Camino Real a Pontevedra, grosso modo en la terminación de la actual Avenida Juan Carlos I y el arranque de la Calle de Rosalía de Castro, y, sobre todo, a lo largo de la

\footnotetext{
${ }^{127}$ Cfr. R. Yzquierdo Perrín, "Santa Susana”, en X.M. García Iglesias, Santiago de Compostela, op. cit., pág. 206-207.

${ }^{128}$ Cfr. M. Murguía, Galicia, Barcelona, 1981 (1ª ed. 1888), pág. 568.

${ }^{129}$ Véase buena reproducción en A. Vigo Trasancos, J. Sánchez García y M. Taín Guzmán, op. cit., 757 (dib.1165).

${ }^{130}$ Cfr. J.M.B. López VÁzquez, "Nuestra Señora del Pilar”, en X.M. García Iglesias, Santiago de Compostela, op. cit., págs. 204-205.
} 


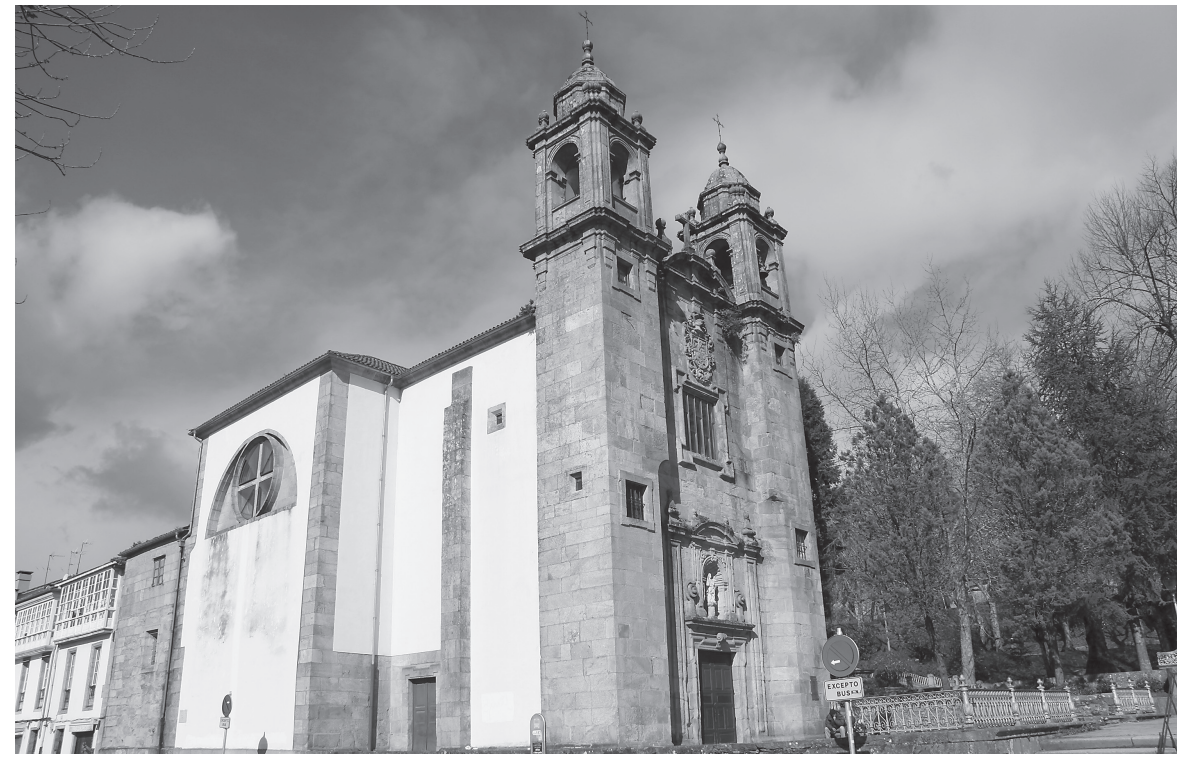

Fig. 15

Iglesia del Pilar.

Rúa Nova de Abaixo que, como se puede comprobar, ya existía en la planimetría de $1796^{131}$ (fig. 4). Tal vez la techumbre próxima al inmueble corresponda a un viejo cuartel demolido en fecha incierta ${ }^{132}$ (fig. 14). Hoy la iglesia es imposible de ver desde Sarela de Abaixo por culpa de la vegetación arbórea exótica de gran altura de la zona.

$$
* * *
$$

Tras todo lo dicho, queda claro que la vista de Juan López Freire, hijo, constituye un testimonio gráfico de valor excepcional debido a la bastante fiel representación de los edificios que conforman la Compostela de finales del setecientos, una ciudad que quizás calificamos con demasiada alegría de "ciudad barroca", cuando no es tal, dada la permanencia de su estructura medieval, sino que, como bien ha explicado Cesare da Seta para casos similares, se trata de una "ciudad del barroco", intervenida con nuevos edificios y espacios regularizados en los siglos

\footnotetext{
${ }^{131}$ Significativamente a esta última se la llama "Calle Nueva".

${ }^{132}$ Véase el plano de la zona de 1788 con la iglesia y el citado edificio; cfr. A. Vigo Trasancos, J. SÁnchez García y M. TAín GuZMán, op. cit., pág. 757 (dib.1165).
} 
XVII y XVIII sin transformar globalmente su identidad ${ }^{133}$. Una Compostela donde se ha desarrollado un particular estilo ornamental, exuberante e imaginativo, el llamado "barroco compostelano", concebido por una célebre nómina de artistas que transformaron para siempre la capital del Reino gallego ${ }^{134}$. A publicitarla con orgullo al mundo parece deberse la realización del grabado, un aparente retrato objetivo de Compostela, como las vistas de 1666 y 1669, otra "metáfora del tiempo y del espacio" como la llamaría Delfín Rodríguez, un testimonio gráfico incontestable de su papel como gran ciudad religiosa, señorial, administrativa, hospitalaria y universitaria destinado a vecinos, visitantes y peregrinos ${ }^{135}$. Suerte que las pocas intervenciones arquitectónicas y urbanísticas de los siglos XIX y XX no han modificado en lo esencial su semblante occidental que ha llegado prácticamente intacto hasta nuestros días.

\section{BIBLIOGRAFÍA}

Barreiro, J.R. (coord.), "Abadologio del Monasterio benedictino de San Martín Pinario en Santiago de Compostela (1607-1835)", Studia Monástica, 7 (1965), 147-188.

Barreiro, X.R., Historia da Universidade de Santiago de Compostela, vol. I, Das orixes ó século XIX, Santiago, 1998.

Barreiro Mallón, B., y Rey Castelao, O., Pobres, peregrinos y enfermos. La red asistencial gallega en el Antiguo Régimen, Santiago-Vigo, 1999.

Beiras García, E., Lucas Ferro Caaveiro e a cidade de Santiago de Compostela, Fundación Caixa Galicia, 2008.

Bonet Correa, A., La arquitectura en Galicia durante el siglo XVII, Madrid, 1984 (1 $1^{\text {a }}$ ed. 1966).

Bugallal y Vea, J., "Armas de la M.N. y M.L. Ciudad de Santiago de Compostela", Gran Enciclopedia Gallega, Santiago-Gijón, 1974, vol. 28, 57-59.

Bustamante García, A., "Visiones de España. Los viajeros del siglo XVI y las representaciones de las ciudades", en M. Cabañas Bravo, A. López-Yarto Elizalde, W. Rincón García, (eds.), El arte y el viaje, Madrid, 2011, 281-294.

Cabo Villaverde, J.L., y Costa Buján, P., Imaxe de Compostela. Unha cidade de pedra nas vellas fotografías, Santiago, 1991.

Cabo Villaverde, J.L., y Costa Buján, P., Compostela. Memoria fotográfica, Santiago, 1996.

Capel, H., Araya, M., Brunet, M. et al., Ciencia para la burguesía, Barcelona, 1983.

\footnotetext{
${ }^{133} \mathrm{Cfr}$. C. da SeTa, La ciudad europea del siglo XV al XX. Orígenes, desarrollo y crisis de la civilización urbana en la Edad Moderna y Contemporánea, Madrid, 2002 (1ª ed. 1996), págs. 157-189. ${ }^{134} \mathrm{Cfr}$. A. Vigo Trasancos, Barroco. La arquitectura sagrada del Antiguo Reino de Galicia (16581763), Santiago, 2012.

${ }^{135}$ Cfr. D. RodríGuez, "De arquitectura y ciudades pintadas. Metáforas del tiempo, del espacio y del viaje", en D. Rodríguez y M. Borobia (comisarios), Arquitecturas pintadas. Del Renacimiento al siglo XVIII, Museo Thyssen-Bornemisza, Fundación Caja Madrid, 18 octubre 2011- 22 enero 2012, Madrid, 2011, págs. 42-46.
} 
Carrete Parrondo, J., "El grabado en el siglo XVIII. Triunfo de la estampa ilustrada", Summa Artis, El Grabado en España (siglos XV al XVIII), vol. XXXI, Madrid, 1987.

Carrete Parrondo, J., Catálogo general de la Calcografía Nacional, Madrid, 1987.

Carrete Parrondo, J., et al., Catálogo del Gabinete de Estampas del Museo Municipal de Madrid, Madrid, 1985.

Carrete Parrondo, J., Fernández Delgado, J. y Vega González, J., "Catálogo", en Estampas. Cinco Siglos de Imagen Impresa, catálogo de exposición, Madrid, 1981.

Castro Santamaría, A., Juan de Álava, arquitecto del renacimiento, Salamanca, 2002.

Caucci von Saucken, P., "La memoria de Santiago y su Catedral en la literatura odepórica compostelana", Compostellanum, 40, núm. 3-4 (jul.-dic. 1995), 367-378.

Costa Buján, P., y Morenas Aydillo, J., Santiago de Compostela 1850-1950, Santiago, 1989.

Couselo Bouzas, J., Galicia Artística en el siglo XVIII y primer tercio del XIX, Compostela, 1932.

Fariña Couto, L., O libro da heráldica galega, Fundación Pedro Barrié de la Maza, 2001.

Fernández Gasalla, L., La arquitectura en tiempos de Domingo de Andrade, Universidad de Santiago, 2004.

Fernández Gasalla, L., "El arquitecto José de la Peña de Toro (1614-1676)”, Compostellanum, 51, núm. 3/4 (2006), 325-368.

Filgueira Valverde, J., "Una panorámica de Santiago en el Viaje de Cosme de Medicis", en Historias de Compostela, Vigo, 1982 ( $1^{\text {a }}$ ed. 1970), 222-226.

Folgar de la Calle, Mª del C., Simón Rodríguez, La Coruña, 1989.

Fontanella, L., Thurston Thompson e o proxecto fotográfico ibérico, A Coruña, 1996.

Fraguas Fraguas, A., O Colexio de Fonseca, Santiago, 1995 (reed. conjunta de Historia del Colegio de Fonseca, Madrid, 1956 y Los colegiales de Fonseca, Cuadernos de Estudios Gallegos, 1958).

Freire Naval, A.B., "La transformación del Hospital Real de Santiago en Parador de Turismo", en A. Bugallo Rodríguez, et al. (comisarios), El Hospital Real de Santiago de Compostela y la Hospitalidad en el Camino de Peregrinación, catálogo de exposición, Santiago, 2004, 529-546.

García M. Colombás, M.B., Las señoras de San Payo. Historia de las monjas benedictinas de San Pelayo de Antealtares, Madrid, 1980

García Iglesias, X.M. (dir.), Santiago de Compostela, Patrimonio Histórico Gallego, Ciudades, Laracha, 1993.

García Iglesias, X.M. (dir.), La Catedral de Santiago de Compostela, Patrimonio Histórico Gallego, Catedrales, Laracha, 1993.

Gómez Iparraguirre, J., Mera Álvarez, I. y Vigo Trasancos, A., "Galicia en las acuarelas de Pier Maria Baldi”, en Neira Cruz, X.A. (comisario), El viaje a Compostela de Cosme III de Médicis, Santiago, 2004, 603-617.

González Méndez, M., y Luaces Anca, J., Santiago de Compostela. A cerca da cidade, Santiago, 2009.

Goy Diz, A., El arquitecto baezano Bartolomé Fernández Lechuga, Jaén, 1998. 
Goy Diz, A., "Nuevas puntualizaciones sobre el llamado Claustro de las Oficinas del monasterio de San Martín Pinario", en Folgar de la Calle, Ma . del C., Goy Diz, A., y López Vázquez, J.M. (coords.), Memoria Artis. Studia in memoriam M ${ }^{a}$. Dolores Vila Jato, Galicia, 2003, 351-370.

Goy Diz, A., "El resurgir de los monasterios en el Renacimiento", en López Vázquez, J.M.B., en Opus monasticorum. Patrimonio, arte, historia y orden, Galicia, 2005, 160-162.

Kagan, R.L. (dir.), Ciudades del Siglo de oro. Las Vistas Españolas de Anton Van den Wyngaerde, Madrid, 1986.

Liber Sancti Jacobi "Codex Calixtinus", traducción de Moralejo, A., Torres, C. y Feo, J., Santiago, 1951.

López, P.A., "El convento de San Lorenzo de Trasouto, extramuros de la ciudad de Santiago de Compostela", Archivo Iberoamericano, 36 (1933), 396-397.

López Ferreiro, A., Historia de la Santa A.M. Iglesia de Santiago de Compostela, vols. VIIIXI, Santiago, 1906-1911.

Marías, F., "Tipología delle immagini delle città spagnole", en C. de Seta (a cura di), Città d'Europa. Iconografia e vedutismo dal XV al XVIII secolo, Italia, 1996, 101-117.

Marías, F., "Imágenes de ciudades españolas: de las convenciones cartográficas a la corografía urbana", en Marías, F. y Pereda, F. (edits.), El Atlas del Rey Planeta. La Descripción de España y de las costas y puertos de sus reinos de Pedro Texeira (1634), Madrid, 2002, 99-116.

Martínez Rodríguez, E., "Demografía urbana de Antiguo Régimen en Galicia: la ciudad de Santiago de Compostela", Obradoiro de Historia Moderna, 13 (2004), 255-276.

Méndez Martínez, G., Cartografía antigua de Galicia, Vigo, 1994.

Muñoz Jiménez, J.M., La arquitectura carmelitana (1562-1800), Ávila, 1990.

Murguía, M., El arte en Santiago durante el siglo XVIII y noticia de los artistas que florecieron en dicha ciudad y centuria, Madrid, 1884.

Murguía, M., Galicia, Barcelona, 1981 (1ª ed. 1888).

Núñez Rodríguez, M. (ed.), Santiago, la catedral y la memoria del arte, Santiago 2000.

Núñez Rodríguez, M., "A la búsqueda del palacio perdido", en Fernández Cortizo, C., González Lopo, D. y Martínez Rodríguez, E. (eds.), Universitas. Homenaje a Antonio Eiras Roel, t. II, Santiago, 2002, 15-30.

Ortega Romero, Ma . del S., "Noticias sobre la construcción del Ayuntamiento de Santiago de Compostela", Cuadernos de Estudios Gallegos, 21, fasc. 63 (1966), 81-101.

Ortega Romero, $\mathrm{M}^{\mathrm{a}}$. del S., "Aspectos urbanísticos del barroco compostelano: voladizos y soportales”, Revista de la Universidad de Complutense, 22, núm. 85 (1973), 163-187.

Pazos, M., El convento de San Francisco de Santiago y sus dos iglesias, la actual y la derruida en 1741 (1518-1862), Liceo Franciscano, Santiago, 1979.

Pazos Pérez, X.X., Chemineas en Compostela, s.l., 1999.

Pérez Costanti, P., "La Torre y el reloj del Colegio de Fonseca”, Notas Viejas Galicianas, t.III, Vigo, 1926, 323-328.

Pérez Costanti, P., Diccionario de artistas que florecieron en Galicia durante los siglos XVI y XVII, Santiago, 1930. 
Pernoud, E., "Le épreuves de sainte Thérèse: la collection de Manuel Navarro", Nouvelles de l'estampe, 1994, 23-25.

Portela Silva, E. (coord.), Historia de la ciudad de Santiago de Compostela, Santiago, 2003.

Raposo Martínez, J., "Un cierto gusto por el arte francés en Santiago de Compostela: el Seminario de Confesores del arzobispo Bartolomé Rajoy y Losada (1690-1772)", Actas del XVIII Congreso del CEHA: Mirando a Clío. El arte español espejo de su historia, Santiago de Compostela, 20-24 de septiembre de 2012, Santiago, 2012, 1.552-1.564.

Rey Castelao, O., "Cistercienses y benedictinos en la Galicia Moderna: evolución numérica y análisis social", en Actas do Congreso Internacional sobre S. Bernardo e o Císter en Galicia e Portugal, Oseira 17- 20 de outubro de 1991, Ourense, 1992, 309-324.

Ríos Miramontes, Mª.T., Aportaciones al barroco compostelano. Un gran mecenazgo, Santiago, 1986.

Ríos Miramontes, Ma .T., La arquitectura civil compostelana en el siglo XVIII, Santiago, 2000.

Rivera Vázquez, E., Galicia y los Jesuitas. Sus colegios y enseñanza en los siglos XVI y XVIII, La Coruña, 1989.

Rodríguez, D., y Borobia, M. (comisarios), Arquitecturas pintadas. Del Renacimiento al siglo XVIII, Museo Thyssen-Bornemisza, Fundación Caja Madrid, 18 octubre 2011-22 enero 2012, Madrid, 2011.

Rosende Valdés, A.A., El Grande y Real Hospital de Santiago de Compostela, Santiago, 1999.

Rosende Valdés, A.A., "La imagen urbanística de Compostela en tiempos de Carlos V", en A. Eiras Roel (coord.), El Reino de Galicia en la época del emperador Carlos V, Santiago, 2000, 637-669.

Rosende Valdés, A.A., Una historia urbana: Compostela, 1595-1780, Santiago, 2004.

Sánchez Rivera, C., Notas Compostelanas. Historias, Tradiciones, Leyendas, Miscelánea, Santiago, s.a.

Senra, J.L., "El Palacio Episcopal”, en Singul, F. y Suárez Otero, J. (comisarios), Santiago. La Esperanza, Santiago, 1999, 73-77

Seta, C. de, La ciudad europea del siglo XV al XX. Orígenes, desarrollo y crisis de la civilización urbana en la Edad Moderna y Contemporánea, Madrid, 2002 (1ª ed. 1996).

Seta, C. de, Ritratti di città. Dal Rinascimento al secolo XVIII, Torino, 2011.

Singul, F., La Ciudad de las Luces. Arquitectura y urbanismo en Santiago de Compostela durante la Ilustración, Santiago, 2001.

Singul, F., y Domínguez Román, B., Palacio de Gelmírez, Santiago, 2001.

Sobrino, Mª.L., y Llano, P. de (coords.), Cartografía básica da cidade de Santiago de Compostela, Santiago, 1990.

Taín Guzmán, M., Domingo de Andrade, Maestro de Obras de la Catedral de Santiago (16391712), Sada-A Coruña, 1998.

Taín Guzmán, M., "Arquitecturas festivas catedralicias: los castillos y las fachadas de los fuegos del Apóstol Santiago", Semata, 22 (2010), 495-518.

Taín Guzmán, M., La ciudad de Santiago de Compostela en 1669. La peregrinación del Gran Príncipe de la Toscana Cosimo III de Medici, Santiago, 2012. 
Tarxetas postais: Santiago de Compostela. Colección Uxio de la Riva Pol, Museo do Pobo Galego, Gran Enciclopedia Gallega, 1981.

Tovar Martín, V., “Arquitectura”, en El arte del barroco, Madrid, 1990.

Vázquez Castro, J., "La Berenguela y la Torre del Reloj de la Catedral de Santiago", Semata, 10 (1998), 118-145.

Vázquez Castro, J., "Castillos en el aire. El inicio del cimborrio gótico de la catedral compostelana", Quintana, 8 (2009), 245-269.

Vicente López, S., "Gaspar de Arce, la muralla y la casa de doña Mencía de Andrade", Compostellanum, 54, núm. 3-4 (jul.-dic. 2009), 375-394.

Vicente López, S., Vega y Verdugo, Peña de Toro y la introducción del barroco en Compostela, Santiago, 2012.

Vigo Trasancos, A., "La iglesia monástica de San Martín Pinario en Santiago de Compostela. Proyecto, fábrica y artífices", Compostellanum, 38, núm. 3-4 (jul.-dic. 1993), 337-361.

Vigo Trasancos, A.,"Santiago 1600-1770. La metamorfosis barroca de un santuario de peregrinación", en Martí Arís, C. (ed.), Santiago de Compostela: la ciudad histórica como presente, Santiago, 1995, 98-107.

Vigo Trasancos, A., La fachada del Obradoiro de la catedral de Santiago (1738-1750), Santiago, 1996.

Vigo Trasancos, A., La catedral de Santiago y la Ilustración. Proyecto clásico y memoria histórica (1757-1808), Madrid, 1999.

Vigo Trasancos, A., "La embajada a España del primer Conde de Sandwich y una vista panorámica de la ciudad de Santiago de 1666", Obradoiro de Historia Moderna, 14 (2005), 271-293.

Vigo Trasancos, A., Barroco. La arquitectura sagrada del Antiguo Reino de Galicia (16581763), Santiago, 2012.

Vigo Trasancos, A. (dir.), Sánchez García, J., y Taín Guzmán, M. (coords.), Galicia y el siglo XVIII. Planos y dibujos de arquitectura y urbanismo (1701-1800), Fundación Pedro Barrié de la Maza, 2011.

Zaragoza Pascual, E., “Abadologio del monasterio de San Martín Pinario (898- 1835)”, Compostellanum, 39, núm. 1-2 (en.-jun. 1994), 209-240. 